New developments in measurement technology relevant to the studies of deep geological repositories in domed salt and basalt

Abelardo L. Ramirez

Nai-Hsien Mao

May 21, 1980

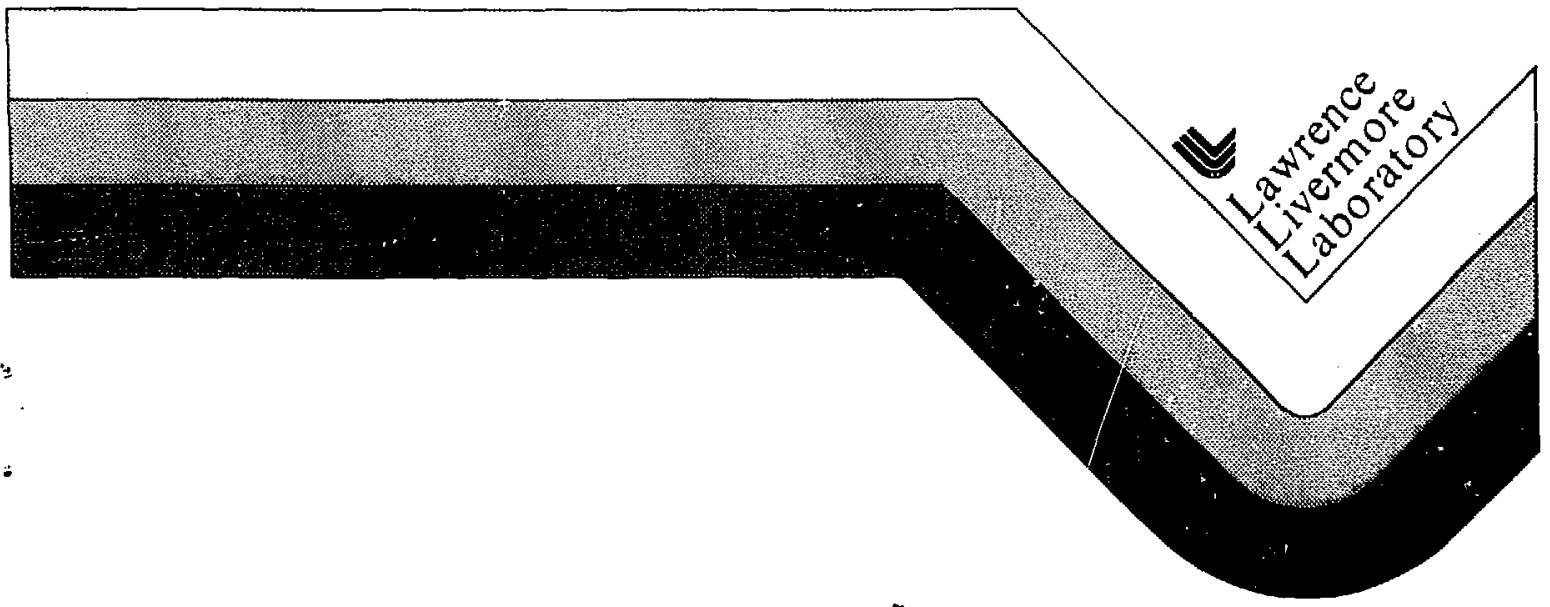




\title{
New developments in measurement technology relevant to the studies of deep geological repositories in domed salt and basalt
}

\author{
Abelardo L. Ramirez \\ Nai-Hsien Mao
}

Manuscript date: May 21, 1980

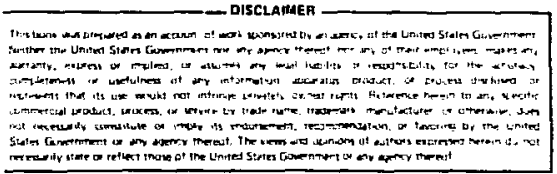

\section{LAWRENCE LIVERMORE LABORATORY University of California - Livermore, California • 94550}




\section{CONTENTS}

Abstract

Executive Summary and Recommendations

vii

Introduction

Other Measurement Program Elements that Need To Be Discussed

I. Factors That Influence Measurements in Basalt and Domed Salt

II. Geophysical Measurements for Subsurface Characterization

III. Absolute Stress Measurements

IV. Stress Change Measurements

V. Displacements and Rock Mass Deformability Measurements

VI. Fracture Characterization

VII. Thermal Properties and Measurements

VIII. Ongoing Research and Development

References 
This repori briefly describes recent geophysical and geotechnical instrumentation developments relevant to the studies of deep geologic repositories. Special emphasis has been placed on techniques that appear to minimize measurement problems associated with repositories constructed in basalt or domed salt. Included in the listing are existing measurement capabilities and deficiencies that have been identified by a few authors and instrumentation workshops that have assessed the capabilities of existing instrumentation with respect to repository applications. These deficiencies have been compared with the reported advantages and limitations of the new developments described. Based on these comparisons, areas that merit further research and development have been identified. The report is based on a thorough literature review and on discussions with several instrumentation specialists involved in instrumentation development. 
A considerable amount of research and development is currently underway to assess or modify existing measurement techniques and to develop new instrumentation that may be useful for studying nuclear waste repository sites. The degree of containment that a rock mass can offer must be evaluated with data obtained from laboratory and field measurement techniques. Large numbers of techniques are available that can measure many parameters of importance to repository studies. However, the unique characteristics of the nuclear waste disposal problem require that stiff requirements be met by many of the techniques that will be used to explore for and monitor repository sites. The large majority of the currently available techniques were not designed with these requirements in mind. As a result, there are voids or deficiencies in existing measurement techniques that will have to be filled by new developments.

These deficiencies include the following: lack of resolution and accuracy, a poor record of. instrument survivability for long time periods, poor instrument performance under high-temperature conditions, and lack of available techniques to measure parameters in situ. There are also serious result discrepancies between some of the various techniques that can be used to measure a given parameter. Other techniques offer information that has inherent ambiguities associated with its interpretation. Research anō development efforts are needed to resolve these problems.

We have listed several new developments that are intended to improve or eliminate some of the deficiencies discussed. other developments are only promising alternatives to existing measurement techniques. The capabilities and limitations of these techniques have been evaluated on a preliminary basis and compared with some of the observations and recommendations made by knowledgable instrumentation specialists who have assessed the existing measurement capabilities with respect to repository applications. 
In general, commercially available techniques should be improved to have better resolution and accuracy, long-term instrument survivability, and fewer uncertainities associated with data interpretation.

The brief discussions presented on these developments have been based on comprehensive literature reviews and on several discussions with instrumentation specialists. All of the techniques presented have been developed recently or are currently under development; consequently, there is an inherent lack of information and experience using them. Because of the lack of information, the evaluation of the techniques presented in the preceding pages should be considered preliminary.

There are several measurement problems that are of particular significance for the exploration or monitoring of repository sites in basalt or domed salt. Basalt flows are commonly characterized by the presence of pervasive joint systems that can dramatically impact the hydrogeological characteristics of these rocks; however, existing techniques that can be used to characterize these fractures are in the early stages of development. Futhermore, well Jogging tools that have proven to be very effective in sedimentary rocks are at present not as effective in igneous rock such as basalt. Igneous rocks have different petrophysical properties as compared with sedimentary rocks, which can be effectively analyzed with appropriate methods of log analysis. on the other hand, salt domes present different measurement problems because of the very different physical properties of rock salt and associated geologic environments. One of the major problems that remains to be solved is how to detect abandoned, uncased exploratory boreholes that penetrate salt domes and can, therefore, endanger the containment capability of salt dome repositories. It is possible that further improvement of existing radar capabilities will solve this problem, but this remains to be seen. Another problem associated with radar exploration as applied to domed salt and other geologic media is that radar measurements still require abundant corroborative evidence for interpretation. Radar measurements are very useful for locating anomalous subsurface features, but are very inappropriate for identifying the type of feature causing the anonaly. 
Corroborative evidence such as that provided by exploratory boreholes is commonly used to ascertain the type of anomalous feature present.

In the preceding paragraph, some of the problems associated with geophysical techniques used in domed salt or basalt terrains have been identified. Nevertheless, geophysical techniques will have to be used to provide essential geological information without excessively disturbing the rock masses being explored. There are numerous conventional geophysical techniques, and several additional ones are under development. In many cases, the interpretation of geophysical data is difficult and ambiguous. Improvement in our interpretation capabilities is one area that merits further research efforts; there are several ongoing research efforts in this area.

According to Romig and Applegate (1980), short-term geophysical research should be directed toward using existing models to design optimum survey techniques for specific sites and to predict the expected results from those surveys. Long-range research programs, in contrast, should concentrate on data processing and interpretation with emphasis on development of models that more accurately describe subsurface conditions and applications of statistical techniques to improve the signal-to-noise ratio.

There are various techniques for measuring absolute stresses, but each has inherent associated problems. The accuracy of these instruments is questionable. Our present understanding of the performance and limitations of existing techniques is rather poor. Currently, it is very difficult to separate instrument error from natural heterogeneity, which may be of significance to the model predictions; this lack of accuracy may have deleterious influence on the reliability of model predictions. Existing in situ stress measurement techniques, with the exception of hydrofracturing, can be used only to depths of several tens of meters. Consequently, these can be used only to measure stresses in a proposed repository horizon after exploratory shafts and tunnels have been excavated. We have briefly discussed new instruments and data interpretation methodologies that have some advantages over conventional techniques. However, more research and development work is needed 
to alleviate or solve the deficiencies associated with absolute stress measurements. More research and development is also needed to improve our understanaing of the performance and accuracy of existing technigues. Based on the accuracy requirements established for model predictions, Gnirk and Hoskins (1979) suggest that stress measurements should be obtained to an accuracy of \pm 108 (this figure was proposed for hard rock sites, i.e., granites, basalts; for shale and salt this value may need re-evaluation). The capabilities of existing instruments (according to Pratt; 1979) are \pm 208 for overcoring, and between 5-10\% (minimum principal stress) and 25ł (maximum principal stress) for the hydrofracturing techniques. The development of techniques that are less expensive and time consuming would be desirable additions to the existing suite of techniques.

stress change measurements can also be obtained with a variety of techniques, but these techniques have not been designed to meet the requirements of temperature and long-term durability necessary to effectively monitor stress changes in a repository. Pratt (1979) has suggested that a very high priority should be placed on research and development work pertaining to stress change measurement instrumentation. It is the consensus of many instrumentation specialists involved in repository studies that existing stressmeters need to be evaluated so that these become more reliable tools. Existing techniques will have to be modified to achieve long-term durability and reliable performance under high temperatures.

We have listed several new developments in the stress change measurements area. Studies and design modifications to improve instrument durability and reliability at high temperatures have been discussed briefly. Two new applications of crosshole geophysical techniques that show promise as techniques used to remotely measure stress changes have also been presented. A new stressmeter, designed for use in salt, that can measure stress changes as well as absolute stress measurements has been described. It appears that further research and development efforts are needed to (a) increase our understanding of the performance of these instruments, (b) establish the potentials and limitations of each technique, and (c) modify existing designs to increase long-term reliability under high-temperature conditions. 
Displacements, rock mass deformatiors, and stress measurements are intimately related to each other and to repository performance. Displacement measurement devices will be exposed to high temperatures and will be required to perform reliably for long periods of time. The accuracy of existing extensometers (20-100 $\mu$ (micron), according to Pratt, 1979) compares favorably with the accuracy requirements for hard rock recommended by Gnirk and Hoskins (1979) with respect to rock stability calculations $(100 \mu)$. Present extensometers become difficult or impractical to use in high- temperature fields. Furthermore, it is difficult to calibrate extensometers because of the lack of calibration instruments that offer higher resolution. The accuracy of conventional rod or wire extensometers may be affected by problems such as creepinduced borehole curvature (in the case of salt) and by "stick-slip" friction.

We have found that the area of displacement measurements has been actively developed in the recent past. A relatively large number of developments were discussed. Four new designs of probe-type extensometers, some of which can monitor displacements in three dimensions, were described. The sliding micrometer is reported to have better resolution than conventional extensometers and thus may be of use for calibrating conventional extensometers. Also described are design modifications and research efforts designed to reduce the errors induced by high temperatures on conventional borehole extensometers. Further research and development work is probably necessary to assess and improve the long-term performance of borehole extensometers and to alleviate or eliminate problems such as corrosion, "stick-silp" friction, and long-term anchor creep.

Rock mass deformability modulus measurements obtained with different techniques often show poor correlation (Bieniawski, 1978a). There are often significant dif- ferences between large-scale tests and borehole jacking tests. Large-scale tests are expensive and time consuming. We have described the results of comparison studies between different measurement techniques to evaluate the reliability of these techniques. Further research and development work should be conducted to completely assess the accuracy and precision 
of these techniques. Borehole jacking tests need further research work in data analysis to improve the correlation with large-scale tests. Assessments of methods that can be used to determine deformability anisotropy should also be conducted.

The general consensus among instrumentation specialists who have assessed the instrumentation capabilities available to characterize fractures in rock is that these techniques are not yet sufficiently developed for repository applications. High-priority research and development work is necessary to bring the state of the art in fracture characterization up to the required level of development for repository applications. The geophysical techniques that can be used generally are capable of providing only qualitative measurements. Other techniques that can be used to map and characterize fractures lack the penetration required to characterize fractures within rock mass. There are no instruments available that have the necessary resolution to monitor fracture aperture for permeability considerations $(1 \mu$, according to Gnirk and Hoskins, 1979). Laboratory measurements needed to understand fracture behavior can be conducted only on relatively small samples that do not adequately represent the rock mass of interest. The development of laboratory facilities that can handle large samples of rock is proposed (Bruce, 1979).

We have also described a new sensitive probe that can detect fine fractures in boreholes. Recent results of field and laboratory studies on acoustic emission that suggest that the acoustic emmission technique is a useful tool in monitoring repository stability and fracture development have been presented. A new theoretical development that may enhance the capabilities of conventional seismic techniques to locate fractures is also discussed. Other new developments are listed by Mao and Ramirez (1980). It is important that significant research and development work be dedicated to the development of techniques that can quantitatively measure frequency, location, geomet.ry, orientation, and the general nature of fractures. Also needed are techniques that can detect changes in fracture properties over time. Because of the impact of fracture aperture on permeability, special emphasis should be placed on techniques that can be used to monitor fracture aperture. 
Thermal properties and temperature measurements can be obtained with in situ or laboratory measurement techniques. Available thermocouple assemblies can provide the desired level of accuracy in temperature measurements, but they may nave long-term drift problems. Research and development work to correct this problem was not in evidence, but should be commenced. There are no in sitú techniques available to measure emissivity, thermal heat transfer coefficients, or thermochemical properties (International Engineering Company, 1979). These can be measured in the laboratory, but che effocts of rock mass discontinuities on these parameters are not well known.

There are other problem areas associated with the measurement technology available for repository studies. Instruments emplaced in boreholes that may be used to monitor the repository should not comproinise the integrity of borehole plugs used to prevent migration of water along the hole. Existing techniques require that cables be used to connect the sensors to the surface. This can reduce the sealing effectiveness of borehole plugs. There are ongoing research efforts to develop telemetry systems that do not require cables to connect the insirument to the surface. Another problem area is related to the integrity of borehole plugs. There are no measurement techniques available for determining the sealing effectiveness of borehole plugs Eor quality assurance purposes or for monitoring any changes that may occur over time. Research and development aimed at developing techniques that can be used to ensure that borehole plugs prevent water migration along the borehole are reconmended. 
The purpose of this report is to survey and briefly 7 iscuss new developments in measurement technology as these relate to studie of deep geological repositorles for nuclear waste. The new developments described include new instruments, nodifications of existing instrumentation, results of recent instrumentation research, and new data interpretation methodologies that can maximize the usefulness of existing instrumentation.* These developments have been compared, as appropriate, with observations and recommendations made by knowledgable instrumentation specialists who have assessed the existing measurement technology with respect to the requirements imposed by repository applications. (International Engineering Company, 1979; Romıg and Applegate, 1980; Lawrence Berkeley Laboratory, 1978; Pratt, 1979; Gnirk and Hoskins, 1979; Cook, 1979). Research and development recommendations made by these authors and the authors of this report are also included. Emphasis has been placed on developments that are particularly useful for domed salt and basalt measurements, though most of the techniques discussed can be applied to other geologic media.

This report is intended to complement the forthcoming report "Nen Developments in Measurement Technology Relevant to the Studies of Nuclear Waste Repositories in Bedded Salt" (Mao and Ramirez, 1980). These two reports complement a state-of-the-art review of existing technology prepared for the Lawrence Livermore Laboratory in 1979 by the International Engineering Company, Review of Geotechnical Measurement Techniques for a Nuclear Waste Repository in Bedded Salt.

* The developments described in this report pertain to geophysical or geotechnical instrumentation, not to geohydrological or geochemical measurement techniques. 
The techniques described have been recently developed or are under current development. Therefore, the adequacy of the brief assessments presented below is strongly dependent on the amount and quality of the information available. In many cases, theze is little available information on instrument performance, potential, and limitations. The instrument evaiuations that follow should be considereã preliminary.

The level of detail about each technique varies throughout the report, primarily because of the amount of information available to the authors. The reported accuracies of several new instruments have been evaluated on the basis of accuracy requirements proposed by Gnirk and Hoskins (1979) for hard rock repositories. Accuracy requirements have been proposed on the basis of modeling requirements and other important factors. These requirements are probably acequate for hard rock (i.e. basalt, granite) measurements. The adequacy of these requirements should be evaluated in terms of the other rock types being considered as candidate media for nuclear waste disposal; if necessary, new requirements should be proposed. 
In the following pages, two important elements of the measurement program for repositories are discussed, i.e., limitations of existing instrumentation and new developments that have some advantages over existing techniques. There are many other measurement program elements that need to be addresseá and resolved. Some of the questions include the following: (a) How much redundancy (different instrumentation types) should be used to provide long-term measurement capabilities? (b) How should the repository be monitored to ensire reliable measurements over long periods of time? Remote sensing? Backup (redundant) instrumentation? In situ calibration procedures performed remotely? (c) What sensitivities, precisions, and accuracies are really needed (as based on modeling requirements) for the measurements chat will be made in different types of rocks? some of these questions have been answered for the case of hard rock (Gnirk and Hoskins, 1979); requirements for measurements in otter rock types have not yet been evaluated. (d) where should the monitoring instruments be located? How many? (e) what type of quality assurance program should be implemented? How does one evaluate an erratic reading? (Hustrulid, 1978). These and other important questions remain largely unanswered. It is outside the scope of the report to discuss all these questions. However, these questions are of great importance for the waste storage problem, and it is recommended that they be given serious and prompt attention. 


\section{FACTORS THAT INFLUENCE MEASUREMENTS IN BASALT AND DOMED SALT}

The geologic characteristics that will affect the containment capabilities of future nuclear waste repositories depend on the types of rocks that will serve as containment horizons. Thus, the features that need to be measured and the measurement accuracy required can vary for different types of rocks being considered for nuclear waste containment. A brief discussion is presented below of some of the important features that need to be measured in domed salt or basalt repository sites.

Many basalt flows are characterized by pervasive joint sets. These joints affect the physical and mechanical properties of a rock mass. Thus, one of the major measurement tasks for basalt repositories is to adeguately characterize these fractures and to understand their effects on the properties of the basalt rock mass. Thick sections of massive basalt flows that have very few joints do exist, but they can be difficult to identify. These sections have to be identified with as little exploratory drilling as possible.

Salt domes present different measurement problems for which different measurement techniques must be used. The flanks of salt domes need to be accurately located so that a repository can be sited to achieve effective containment of the nuclear waste. Salt has low strength and high creep potential, particularly at elevated temperatures. Because salt is a good transmitter of electromagnetic waves, radar is a very promising tool for salt exploration. Instruments used for in situ measurements must be designed to take creep properties into account. Absolute stress measurements obtained with inclusion devices must be made after stress equilibrium is reached between the salt and the inclusion. Borehole extensometers must perform adequately even if creep-induced borehole curvature affects the alignment of these instruments. Salt brines are highly corrosive and may reduce useful instrument life. Salt domes can be associated with min- eral resources that have attracted exploratory drilling in the past and may attract drilling in the future. old exploratory boreholes that may endanger the containment integrity of a salt dome repository must be detected by the measurement techniques that will be used to explore a given site. 
Subsurface characterization of sites is of fundamental importance in the design and construction of a repository. Various geophysical methods can be used to characterize the subsurface properties of repository sites. Geophysical techniques combine two approaches: (1) the science of remotely measuring physical phenomena from the surface and from boreholes, and (2) the art of interpreting those measurements in terms of inferred deep geologic and engineering parametars. Surface-based geophysical surveys can produce continucus profiles of the depth to rock and, perhaps more significant, provide the additional advantitages of minımizing the intrusive disruption of a site. Underground measurement techniques generally have better resolution and arcuracy than surface techniques because of their closer proximity to the area of interest. The Iuternational Engineering Company (1979) has listed and described all of the conventional geophysical techniques. General assessments of the application of geophysical techniques to nuclear repository site characterization (Romig and Applegate, 1979) and to underground construction (D'Appolonia and siaw, 1979; Goodman, 1979) have been published recently. Cited below are four important recommendations and observations concerning the cirrent state of the art of geophysical techniques as applied to repository investigations.

Geophysical measurements often require considerable interpretation, which is limited by the extent to which theoretical models describe the "real" earth. Typical assumptions such as isotropy, homogeneity with layers, constant coefficients etc., are usually not valid (Romig and Applegate, 1979) .

- As many borehole techniques as feasible should be run in the test boreholes. Each method can add to the value of the total information obtained. Methods should be correlated to enhance the value of the information (International Engineering Company, 1979). 
- There are no definitive guidelines concerning the capabilities and limitations of various geophysical techniques based on generalized models, because the effectiveness of each technique is strongly controlled by site-specific factors (Romig and Applegate, 1979).

- Geophysical measurements should always be supplemented by rock classification and description, index testing, and some direct tests (Goodman, 1979). Currently, the geophysical methods available to measure the degree of weathering and fracturing, rock deformability, strength, and in situ stresses are not reliabie. Consequently, data obtained using these methods shoula be supplemented with other information. There are borehole instruments that can be used to measure in situ stresses and rock deformability. Measurements of parameters such as rock quality designation (RQD) can be used to estimate degree of fracturing.

Several new promising geophysical instruments are described below. Also discussed are data interpretation methodologies that may be used to maximize the usefulness of geophysical techniques. In general, the developments cited below are intended to improve existing data interpretation capabilities and geophysical tools and to develop instruments that can improve the existing state of the art in geophysical technology.

\section{Seismic Reflection Techniques}

Farr (1979) has reviewed the state of the art in high-resolution seismic reflection techniques as applied to mining exploration and underground construction. He estimates that when a typicil velocity of $2.5 \mathrm{~km} / \mathrm{sec}$ is assumed for the formation, then the minimum detectable bed thickness will be $1 \mathrm{~m}$ thick if the predominant reflection frequency is $200 \mathrm{~Hz}$. Existing seismic amplifiers designed for the "conventional" frequencies (approximately $20 \mathrm{~Hz}$ ) are limited in their dynamic range and thus limit the resolvtion of existing seismic reflection instruments. Improvements in the dynamic range of existing seismic amplifiers are needed to increase the resolution of seismic reflection techniques. 
Conventional seismic reflection measurements are used to probe subsurface structures deeper than approximately $200 \mathrm{~m}$. Conventional seismic techniques are not very useful for searching out suitable repository access shaft locations, because critical geologic factors that affect shaft construction can be found at the shallower depths. A new seismic reflection system designed for shallow exploration has been developed for the u.s. Bureau of Mines. The Westinghouse Electric Corporation has designed, constructed, and demonstrated a two-channel seismic reflection system that uses high-frequency $(100$ to $6,000 \mathrm{~Hz})$ seismic signals for the mapping of shallow reflectors (up to approximately $200 \mathrm{~m}$ ) (Kehrman, 1977). The source of the acoustic frequeicy signals is a 600-lb-force vibrator that delivers compressional waves into the earth in the form of a sinusoidal wave either of a single frequency or as a sweep of frequencies. Geophones are deployed in circular arrays of 19 sensors connected in series to inc-ease the signal-to-ncise ratio. The system has been tested at a shallow sedimentary uranium deposit. Resolving power appirs to be enough to detect shale lenses anà small-scale fluctuations on the surface of reflecting horizons.

The structural information that can be derived from seismic data displays inc'udes (in addition to the location of faults, sand channels, and partings) such information as the unique identification, thickness, and lateral persistence of particular beds. Density and velocity changes across the upper and lower bed interfaces cause seismic reflections from essentialiy identical formations to have different anplitudes and frequencies. This identification of rock types using seismic wavelet characteristics is an extremely useful supplement to the more familiar structural seismic profiling. It can provide the designer with valuable regional information about the edges of a repository horizon and depositional environments (Farr, 1979). 
Rock mass quality indexes such as $\mathrm{RQD}$ and numbers of fractures per meter provide very important design information for underground construction. The measurement of these parameters is normally made on rock core recovered from drilled boreholes. New correlations are described below that relate these important parameters to geophysical measurements taken in the field. These investigations minimize the need for exploratory drilling. During the last two decades, seismic parameters, mainly longitudinal wave velocities obtained through refraction investigation, have been widely used as indicators of rock mass quality. Sjogren et al. (1979) discussed the field correlations between several seismic parameters and varying geologic factors such as joint frequency, rock type, mineral content, and structure. They observed a strong correlation between fracturing and seismic parameters. When the numbers of fractures per meter are plotted vs longitudinal wave velocity and a regression curve is constructed, the dispersion observed between the curve and the real measurements is small for unweathered igneous and metanorphic rocks. Many basalt flows are strongly jointed; the relationship observed here between the number of fractures and the longitudinal wave velocity should be very useful for identifying thick sections of massive, essentially joint-free basalt or granite as a repository site for nuclear waste.

They further concluded that the dispersion of the dynamic Poisson's ratio, and that of the dynamic elastic moduli, gives an indication of the homogeneity of the rock mass. By plotting the dynamic moduli of elasticity of the different rock masses in relation to their corresponding dynamic Poisson's ratio, it becomes possible to indicate where the optimum rock conditions exist with respect to fracturug for an actual site.

Although results of these calculations can very well be utilized before any drilling data are available to predict the fracturing of rock masses, these relations should be re-evaluated when boring results are available. 
Over the past decade, interest has revived in the use of electromagnetic radiation for probing the earth. Numerous groups have been involved in the application of radar or radio transmission measurements to the study of salt, coal, and the general engineering properties of rocks. Fowler and Rubin (1978) used a short-pulse radar with a center frequency of about $120 \mathrm{MHz}$ to map the roof stratigraphy of a coal mine. They were able to map the major roof layers between two boreholes $33 \mathrm{~m}$ apart to a depth of $10 \mathrm{~m}$. Radar reflections, though small, can be seen from ranges longer than $7 \mathrm{~m}$. Clay veins in a coal pillar may also be detected. With better acquisition techniques, as well as better automated processing and interpretation techniques, the penetration depth can be extended to $10 \mathrm{~m}$ and beyond.

Ensco, Inc., developed and initiated the field evaluation of a shortpulse borehole radar system for subsurface site investigation in boreholes and tunnels (Rubin et al., 1978). The borehole antenna developed can either aquire data from only one hole or be used to transmit and receive signals between holes (crosshole mode). Most of the energy transmitted by the radar antenna is distributed in the range of $50 \mathrm{MHz}$ to $150 \mathrm{MHz}$. The borehole radar system was field evaluated at two sites in rock. One test site featured an array of four subvertical boreholes on a line about $5 \mathrm{~m}$ to $17 \mathrm{~m}$ apart and about $80 \mathrm{~m}$ deep in a rock mass of weathered to unweathered quartz, mica schist, and gneiss. At the other test site, three closely spaced ( 3 to $7 \mathrm{~m}$ ) subhorizontal holes were drilled to a depth of $33 \mathrm{~m}$ in unweathered diabase. When both single and crosshole measurements were correlated with the core data, the measurements were found to be strongly correlated to specific known rock structures. The phase velocity of electromagnetic waves is a function of the moisture conditions of the propagation materials. The phase velocity is then related to the degree of fracturing, lithology, weathering, and hydraulic conditions. A better understanding of the effects of these parameters on the phase velocity is the key to interpreting radar data. 
Ensco, Inc., is also developing a synthetic pulse radar system for the U.S. Bureau of Mines (Leckenby, 1980). This system has the potential of achieving greater penetration and more accurate location than the shortpulse radar system. Because the Ensco system has greater control of the frequency content of the pulse, it can selectively transmit oniy frequencies that penetrate a given rock type best, achieve greater effective pulse power, and reduce background noise by sharply tuning the receiver and antennas to each frequency. Each frequency is transmitted individually, and the amplitude and phase of the received signal are measured and recorded. The data are then processed to produce time pulses that can be interpreted in a fashion similar to conventional radar measurements.

Probably the most useful application of the synthetic pulse (Ensco) and the short-pulse radar system is for bedded or domed salt characterization. Some types oF salt are better transmitters of electromagnetic waves than any man-made material developed specifically for transmitting radar waves. Unterberger (1979) discusses four radar systems having varying penetration depth (range) and resolution. The general pattern is that the higher the frequency used the shallower the depth of penetration, but the higher the resolution.

The "Echo" radar system was developed for high-resolution, $(1 \mathrm{~cm})$ shortrange $(25 \mathrm{~m})$ probing of salt. The system sends out a continuous wave that is frequency modulated. At $4300 \mathrm{MHz}$, its power output is about 1 watt. This system is best used during repository characterization within a salt dome to probe through a salt floor, wall, or ceiling for fractures, cavities, etc.

The "Charlie" radar system is a battery-operated, pulsed radar probing system that uses a 440-MHz pulse with a $0.3-\mathrm{msec}$ pulse width. The maximum range in salt obtained with this system is $940 \mathrm{~m}$. This system has located salt-anhydrite interfaces, dome, flanks, and cased boreholes in a salt pillar in various salt mines. 
The "Bravo" radar system is a modified version of the shoran radar originally used in Forld Har II. Results obtained with the system are generally much like those obtained with the charlie system; the advantage of Bravo is that its lower frequency (230 MHz) and higher power $(20 \mathrm{~km})$ usually allow deeper penetration of the salt.

The "Alpila" radar system was designed specifically to minimize the attenuation losses caused by any water present in salt formations. It utilizes a low-frequency (30 $\mathrm{MHz})$ pulse for greater range (more than $2,000 \mathrm{~m})$, but it has lower resolution. In the Grand saline salt mine of East Texus, reflections were received from the dome flank and a brine cavity.

Radar systems and other high-frequency electromagnetic probing techniques can be very useful when they are used to probe salt rock masses. These systems can be ussed successfully to locate several subsurface features of interest. It is very difficult, however, to determine the types of features or phenomena existing at the identified locations. These systems usually answer the "where" part of the question very well, but are not very useflil in determining the "what" part. To resolve these interpretation problems, carefully planned field experiments should be conducted to correlate electromagnetic measurements systematically with varying geologic conditions determined from borehole cores and other exploration techniques.

Existing radar systems have been used successfully to detect cased boreholes in salt (Unterberger, 1979), but techniques that can be used to detect uncased boreholes in salt or other rock media are not available at present. This limitation is particularly critical in the case of domed salt exploration because numerous uncased exploratory borings may have been drilled in the past around and through salt domes. Tarantolo and Unterberger (1978) have indicated that it is at least theoretically possible to detect boreholes with a radar system. Further development of 
radar systems may provide a useful tool that can be used to detect uncased boreholes. This is one area in which further research and development is recommended.

Signal Enhancement for Acoustic Well Logging

When acoustic measurements are used, the compressional wave arrives at the acoustic receiver first because the velocity of a shear wave is substantially less than the compressional wave velocity. However, the amplituäe of the shear wave on arrival is often much greater than that of the compressional wave. Thus, there is no ideal gain setting for both waves. Buckner (1979) describes a system that can alleviate this problem by using variable-gain amplifier and negative feedback to control the gain of subsurface amplifiers used for subsurface well logging. The amplitude of each succeeding positive half-cycle of the earlier arriving compressional wave is measured, and a negative feedback is supplied to the amplifier if the measured amplitude exceeds $50 \%$ of the full scale. Thus, the succeeding amplitude is suppressed and system overloading is avoided.

This system should be useful for any type of methods and apparatus for measuring various formation parameters associated with the generation and reception of acoustic waves.

\section{Anaizsis of Borehole Data in an Evaporative Sequence}

The most useful well logging measurements in evaporative seqr nce such as those associated with salt deposits are gamma-ray, neutron-neutron, density, and acoustic relocity logs. The high resistivity of salt and the low resistivity of commonly used drilling fluids (brine muds) make it difficult to obtain measurements of electrical properties in an evaporite sequence. Daniels et al. (1979) report on the test of a single-coil induction probe that minimizes these problems. The measurements obtained so Ear correlate well with conductivity changes that would be expected to 
occur in an evaporite sequence. The results show conductivity anomalies in the salt that may be related to moisture variations.

Complex structural features (faulting and folding) are difficult to interpret with individual logs. Some complex folding can be associated with the diapiric intrusion of salt domes. In order to compare the well $\log$ responses of interbed sequences, it would be helpful to rotate the interbeds from their present dip angles to a common dip angle. An alternative solution is to normalize the well $\log$ response values. This can be done by plotting the percent frequency of occurrence of well log response values (digitized at $0.15-\mathrm{m}$ intervals) for the interbeds (Daniels et al., 1979). Limbs of a fold that intersect the drill hole at different dip angles yield similar distribution patterns on these percent frequency plots. The frequency plot technique may also be useful for tracing marker beds between different holes.

\section{Borehole Geophysics in Igneous Rocks}

Igneous rocks such as basalts usually present different petrophysical properties (such as porosity, density, resistivity, and mineralogy) from those of sedimentary rocks. Many of tie techniques available to interpret geophysical logs have been developed for petroleum exploration in sedimentary rocks. For this reason, conventional geopiysical logging techniques may not be useful and petrophysics may have to be used to develop appropriate methods of log analysis. Keys (1979) evaluates the various aspects of borehole geophysics pertaining to igneous rocks. He concludes that the natural gamma $\log$ is as useful for the determination of lithology in igneous rocks as it is in sedimentary rocks. Gamma-gamma logs may not be as useful in many igneous rocks, but neutron logs have proven to be very useful. Several types of acoustic logs can be quite useful in igneous rocks. The acoustic televiewer is probably the single most useful tool for obtaining data on the location, orientation, and character of fractures. It is probably more universally applicable in igneous than in sedimentary rocks because the harder rocks provide 
superior reflection, and drilling mud and mud cake are usually not a problem. The acoustic televiewer can also provide lithologic information on the strike and dip of contacts between lithologic units. Electric logs, including all types of resistivity, conductivity, induced polarization and spontaneous potential are particularly difficult to interpret in igneous rocks.

Two major secondary features of igneous rocks - hydrothermal alteration and fracturing - not only affect log response but are important anong the results expected from log analysis. Identification and characterization of altered zones can provide data bearing on both past and present aigration of fluids. Most of the fluid movement in igneous rocks is caused by flow in fractures. Logging in igneous rocks to depths as great as $3,000 \mathrm{~m}$ has failed to reveal unfractured rock sections that exceed 200 $\mathrm{m}$ in thickness (Keys, 1979).

The interpretation of lithology from geophysical well logs obtained from igneous rocks is largely dependent on the amount of corroborating data available and the interpreter's Experience. For each new area, it is absolutely essential that some core data be available to develop interpretative criteria. Computer cross plots that compare different geophysical parameters with each other are among the most useful techniques for developing an understanding of log response in new rock types.

Several new geophysical methodologies and instruments for subsurface character tzation have been described above. We will not recapitulate them briefly. For basalt, the most important measurement goals are the characterization of the fractures or joints commonly associated with it, and the identification of a thick section of massive, essentially joint-free basalt. The best approach probably involves two techniques: seismic techniques involving geophysical logging and supporting computer programs, and highresolution, high-redundancy, continuous-reflection profiling. Radar techniques are probably the most useful technique for domed salt exploration. 
An important aspect of the development of improved ground probing radar methods is an understanding of the role played by the physical properties, namely the electrical resistivity and dielectric constant. The electrical resistivity and dielectric constant of rocks depend upon the lithology, the water content, and the frequency. Water content is the most important parameter in determining both the magnitude and the frequency dependence of the electrical properties of rock masses. Further research in these areas is the key to understanding the capabilities and limitations of radar and radio transmission methods (Keller, 1979). The interpretation of radar measurements can be a very ambiguous process. Radar measurements can be used successfully to locate anomalies within rock masses; however, these techniques have not proved successful for identifying the types of geologic features that produce the anomalies or reflections. Field experiments in which abundant corroborating data from other exploration techniques can be correlated with the results of radar surveys are necessary to improve existing interpretation capabilities. It is possible that further development of radar systems mir. $r$ produce an exploration tool that could be used to detect abandoned, unrased boreholes whose exact location is unknown to us. In addition to radar techniques, high-resolution seismic reflection profiling should be very effective for domed salt exploration.

The application of borehole geophysical logging to the exploration of igneous rock masses is still in the early stages of development. Present knowledge is empirically derived, and there are few quantitative log interpretations. Significant improvement in the state of the art can be achieved with further research in areas such as developing theoretical petrophysical models for the response of various logging tools in igneous rocks and modifying or redesigning logging tools for igneous rock exploration (Keys, 1979). 
Numerous techniques currently exist for the measurement of the absolute state of stress in rock masses. The International Engineering Company (1979) has listed and described all of the techniques conventionally used to measure absolute stress. Few of these techniques are popularly used because of the difficulties associated with measuring absolute stress. Absolute stress measurements are usually obtained by the stress relief method or less frequently by hydrofracturing or jacking. In the stress relief method, a portion of the stressed rock containing the stress measuring device is cut free (i.e., stress relieved) by overcoring. The deformation measured can then be related to the stresses affecting the rock that contains the measurement device. In the hydrofracturing method, the rock mass is hydraulically fractured; the state of stress can be determined on the basis of the orientation of the fracture and the pressure required to fracture the rock. Because it is necessary to fracture the rock mass using this technique, stress measurements should be conducted some distance from the repository. Flat jacks can also be used to measure absolute stresses; a flat cell is placed in a slot that has previously been cut into a rock face. The cell is then pres- surized, forcing the steel membranes against the sides of the slot. Reference pins that had previously been embedded in the rock are monitored during pres- surization of the cell. The pressure required to return the rock to its virgin state is assumed to equal the rock stress acting normally on the flat jack.

A few assessments of the state of the art available to measure absolute stresses with respect to repository needs have recently been published (Pratt, 1979; Lawrence Berkeley Laboratory, 1978; International Engineering Company, 1979). Gnirk and Hoskins (1979) conclude on the basis of modeling requirements that the required measurement accuracy for in situ stress measurements is \pm 108 (or to within 1 mega pascal (MPA)). Pratt states that the current state of the art is approximately $100 \mathrm{psi}$ (20\%) for borehole technigues. For hydrofracturing techniques, Pratt suggests that minimum principal stresses can 
be measured with an accuracy of 5-10\%, and tae maximum principal stresses can be inferred with an accuracy of 25\%. The Lawrence Berkeley Laboratory (1978) suggests that there are various techniques to determine absolute stresses in rock, but that the accuracy of each is questionable and that the correlation of results from different techniques is not good. Pratt also suggests that research and development work on absolute stress measurements be given a high priority. He proposes that research is needed to improve the accuracy and capabilities of existing techniques and to develop the capability to measure absolute stress in boreholes deeper than 50 - $100 \mathrm{~m}$. They also recommend research to advance our understanding of the performance and limitations of existing techniques and to seek and develop promising new ones. The International Engineering Company (1979) suggests the development: of probes that can measure stresses in soft and fractured rocks.

Several new and promising techniques that measure absolute stresses are described below. Also described are recently developed data-interpretation methodologies that can be used to improve the quality and reliability of the measurements obtained in the field. Because all of the measurement techniques presented have been developed recently, they are still in the process of being evaluated and many of the problems or advantages associated with them are difficult to assess for lack of field experience and data.

\section{Acoustic Enission Technique To Detect Absolute Stress}

Ranagawa et al. (1976) discussed the use of acoustic emission signals to measure absolute stresses in rock. The method is not limited by the assumptions normally required by stress-relief methods. It has a significant additional advantage over conventional overcoring techniques, which are limited to depths of 75 - 100 ft. The acoustic emission method uses conventional core samples that are later tested in the laboratory; thus, it is not limited to the limited depths of the overcoring methods. 
The acoustic emission method to measure absolute stress utilizes the "Kaiser effect" of acoustic emission signals. The Kaiser effect is a phenomenon observed when a sample is compressed uniaxially; the number of acoustic emission events increases drastically above the maximum stress level previously experienced by the sample. When samples of different orientations are prepared from rock cores, the measured Kaiser effect on these samples reveals the in situ stress level in various directions. The results from tests in tuff samples are strongly correlated with those obtained by overcoring. The average stress component estimated by the acoustic emission method is larger (though still within the uncertainty of the measurements) than the average result from overcoring. Kanagawa et al. suggest that this difference may be caused by the fact that the Kaiser effect corresponds with the maximum stress that has affected the sample over time - not just with present stresses.

\section{Least-squares Calculation of Hor izontal Stresses}

Absolute stress measurements are generally characterized by a significant scatter of the results. Thus, the analysis of absolute stress measurements can involve a significant amount of judgment, which may be erroneously biased. Duvall and Aggson (1980) have develor d a leastsquare method to calculate stress components in the horizontal plane; their method minimizes the experience and judgment ractors that previously affected the analysis of stress measurements. Their method requires that three diametral deformation measurements be made along a vertical hole. The least-squares analysis provides a means of determining the multiple correlation coefficient and the variance for a set of deformation measurements.

\section{Absolute Stress Measurements in An isotropic Rock Masses}

The stress-relief measurement techniques commonly used to measure absolute stress require a few simplifying assumptions. The assumption that the rock be isotropic is seldom approached by rock masses and hence may 
lead to grossly erroneous results in certain cases. Ribacchi (2977) has discussed several interpretation methods that can be used to avoid the errors entailed by this assumption.

\section{Absolute Stress Measurements with Cast In-Place Epoxy Inclusions}

Hard and soft inclusion probes have been useả conventionally to measure absolute stresses for geotechnical applications. As the rock containing the inclusion is overcored, it deforms; at the same time, the inclusion itself is deformed. Stresses in the inclusion are measured with hydraulic capsules, birefringent glass plugs, magnetostrictive effects, and electric resistance strain gauges (Jaeger and Cook, 1976).

A new type of inclusion is being develope.j at the University of California, Berkeley (Nolting and Goodman, 1979). The basic technique is to drill a small-diameter pilot hole from the bottom of a larger hole, then to fill the smaller hole with epoxy. After the epoxy hardens, it is overcored, and the rock annulus containing the cylindrical epoxy inclusion is removed. Assuming a compressive stress field, the rock annulus will have expanded upon overcoring and the inclusion will now be in tension. The removed core is then sectioned with a diamond saw. The strains in the epoxy can then be measured. The measurement technique being developed by Nolting and Goodman involves drilling a hole through the center of a strain gage rosette embedded in the inclusion. The subsequent relaxation strains can then be monitored and related to the pre-existing stresses in the inclusion.

Material properties of both epoxy and rock must be known. In addition, certain corrections are necessary for thermal and casting stresses üs well as time-dependent behavior on the part of the epoxy. The corresponding stresses are then calculated; from these calculations, the field stresses are computed using an analytical solution. This method has one advantage over other overcoring techniques that make use of electrical devices to measure strain. Normally, these electrical devices are 
monitored during the overcoring operation, and the cables connecting these devices to the surface have to be protected carefully. In contrast, the procedure proposed by the authors does not require monitoring of the strain gauges during the overcoring operation; hence, there are no cables to contended with. It must be remembered, however, that this technique is still being developed and evaluated.

\section{Diagnostic Stress-Relief Curves for Absolute}

Stress Heasurements obtained by Overcoring

The overcoring method is one of the most common stress-relief methods to measure absolute stresses. The reliability of the stress data obtained by this method is affected by several factors. Erratic or incorrect stress values may result if the overcore hole is eccentric with respect to the instrument hole or if the instrument malfunctions. Blackwood (1978) has developed a methodology that indicates whether the measurements obtained by the overcoring method are valid or if they have been affected by external influences that have led to an incorrect stress analysis.

In principle, the overcoring method consists of overcoring an initially circular borehole in a stressed rock mass by cutting a circular concentric groove around it. The inner borehole is instrumented in such a way as to measure deformation or strain change induced by stress relief as the rock annulus containing the measuring device is isolated from the rock mass. The amount of deformation measured in this manner can then be related to the absolute stresses that exist in the rock mass where the measurements have been taken.

The forms of the stress-relief curves (graphs of deformation caused by stress relief vs overcoring distance relative to measuring sensor position-) obtained from data observed during overcoring can be predicted theoretically. If these theoretical curves are compared with those obtained from actual data, the validity of the observed data can be assessed. 
Blackwood has developed stress-relief curves predicted from theory that can be considered diagnostic of stress relief. These curves are derived for all sensor orientations of a borehole instrument affected by a threedimensional stress field. The methodology suggested by Blackwood can be very useful because it provides the previously unavailable capability of detecting erratic stress data on the basis of theoretical considerations - not on the basis of judgment, which can be erroneously biased.

\section{Absolute Stress Measurements in Salt}

\section{with a Vibrating wire Stressmeter}

Vibrating wire stressmeters have been used in the past to measure stress changes over time, but not to measure absolute stresses. Recent laboratory and field work in salt by Cook and Ames (1979" tes a new improvement: the vibrating wire stressmeter can be $u$.ueasure absolute stresses without stress relicf caused by flowage or creep of the salt in which the instrument is installed. Field experience with their gauge even at elevated temperatures has indicated excellent long-term stability and reliability except in the presence of standing water (Schrauf, 1980).

Absolute stress measurements will be needed for several purposes during the development of a repository. The measurements will first be needed to prepare design specifications to construct the repository, then to provide base-line data that can be used to assess pre-emplacement and postemplacement rock behavior. Various techniques are available for measuring absolute stresses, but they have associated problems that tend to reduce the usefulness and reliability of the instruments. New developments have been described that show promise for solving some of the problems associated with conventional techniques. These developments need to be evaluated further under field conditions to establish their potentials and limitations, as well as theix accuracy and resolution and compared with parameter sensitivity analysis provided by the modeling efforts. 
Stressmeters (devices used to measure stress changes) have been used routinely in the past for mining and engineering applications. Stressmeters can also play an important role during several stages of repository development. These instruments will be used to monitor stress changes in the rock during during three stages: heater tests, construction of the repository, and the monitoring phase after waste emplacement has commenctd. Stress change measurements will be needed to validate models, to assess rock mass stability, and to understand rock mass behavior. Stressmeters used for repository applications will have to operate reliably for long periods of time and under the effects of such factors as high temperature, corrosive agents, and water.

Recommendations for research and deveiopment work with respect to repository requirements have been proposed by several authors and instrumentation workshops. The International Engineering Company (1979) proposes that new inclusions be developed that can monitor stress changes parallel to the borehole axis in addition to the existing capability of measuring stress changes perpendicular to the borehole axis. It also suggests that a better understinding of rock creep effects on gauge performance is needed. The Lawrence Berkeley Laboratory (1978) suggests that stressmeters such as the vibrating wire stressmeters and flatjack need further evaluation in order to be reliable quantitative tools. Pratt (1979) suggests that a very high priority should be placed on research and development work pertaining to the measurement of changes in stress over time; he also suggests that modifications of existing techniques such as Irad vibrating wire stressmeters and U.S. Bureau of Mines (USBM) borehole deformation gauges be conducted to increase reliability. Pratt also emphasizes that techniques must be developed for use in the nuclear waste environment; candidate technique, suggested for development include Commonwfalth Scientific and Industrial Research Organization (CSIRO) gauge and borehole flatjack systems. Pratt states that stressmeters used for repository applications will have to operate reliably at temperatures as high as $200^{\circ}$ to $300^{\circ} \mathrm{C}$. 
Several new developments that address a number or the research and development needs presented above are discussed in this section. These developments include the application of cross-hole acoustic surveying to stress change monitoring; a new stressmeier designed for salt; and tests, calibrations, and design modifications performed on conventional stressmeters (vibrating wire stressmeters and USBM borehole deformation gauges) to increase their reliability and accuracy when they are subjected to high temperatures.

\section{Cross-Hole Acoustic Measurements To Monitor Stress Changes}

Cross-hole acoustic measurements have conventionally been used for site characterization both to estimate the in situ elastic modulus of rocks and to roughly estimate the degree of fracturing existing in the rock mass between the transmitting and receiving holes. Cross-hole measurements characteristically provide parameter measurements that are averaged over the distance between boreholes. Other techniques, such as the devices conventionally used to measure stress changes, require that measurements be made at a point that often is not representive of the typical conditions of a rock mass.

Paulsson and King (in press, 1980) report that cross-hole acoustic measurements, conducted as part of a heater experiment in stripa granite, can provide an excellent method for monitoring stress changes in crystalline rocks. A comparison of the behavior of the p- and s-wave velocities and the behavior of the stress measured in two vertical holes near the heater shows that these are remarkably similar. The authors suggest that as the rock mass is heated, thermal expansion tends to close open fractures and to increase the normal stress across those already closed. It is possible that fracture closure may enhance acoustic coupling between rack on either side of the fracture, and consequently seismic velocity and attenuation changr. If an estimate of the stress change required for fracture closure can be obtained, this technique may be useful for monitoring stress changes. Hence, the authors suggest that 
the cross-hole acoustic technique provides an excellent method for monitoring stress changes.

The acoustic cross-hole technique has some advantages over conventional devices such as vibrating wire stressmeters and borehole deformation gauges. Cross-hole surveying can be used to monitor stress changes around waste cannisters without having the necessary instrumentation affected by the high rock temperatures induced by the waste. Hence, the temperature stability requirements for this type of instrumentation would be significantly less than those imposed upon stressmeters that have to be implanted very close to the canisters. Cross-hole acoustic data can be used to monitor changes in the rock moduli as the rocks are heated. But this method also has limitations. The acoustic surveying method averages the stress change measurements over the distance between the transmitting and receiving boreholes. However, the variatior:3 in stress change along this distance may be of significance for heater test calculations, model validation, or rock stability calculations. Thus, certain applications may require that stress changes occurring at a given point be monitored with conventional stressmeters. The change in wave velocity used to monitor stress changes depends on fracture behavior as these changes in stress occur. Salt is not likely to contain fractures, and therefore this technique is not likely to work in salt. This acoustic technique has been used only once to monitor stress changes, and consequently additional field experiments are needed before the technique can be accepted as a trusted, quantitative tool to measure changes in stress over time.

\section{Cross-Hole Geotomography Proposed as a Tool To Monitor Stress Changes}

Lytle (1980) and others oropose on the basis of results from recent field experiments that the geotomography technique (Dines and Lytle, 1979; Lytle et al., 1978) can be used to monitor stress changes. In these experiments, electromagnetic borehole-to- borehole transmissions were performed at the end of a tunnel and a geotomograph was constructed to 
show the variation of signal attenuation between the boreholes. A uniform attenuation rate was detected. According to Lytle, the best explanation for the abserved attenuation may be that the transmission losses are related to the stress relief expected around the mine. As the rock is stress relieved, some of the fractures within the rock mass tend to open, and transmission losses result. If the proposed explanation is correct, then the geotomography technique may be useful for monitoring stress changes indirectly. The range of stress changes and the accuracy with which these may be detected depend on the behavior of the fractures as the stresses increase or decrease; the relationship between fracture behavior and stress changes is not well understood at present. Consequently, the usefulness of this technique for monitoring stresses quantitatively may be limited. The use of the cross-hole geotomographic technique to monitor stress changes should be considered to be in the early stages of development; further field tests are needed to assess its usefulness as a tool for monitoring stress changes.

\section{Stressmeter for Stress Change Measurements in Salt}

A new stressmeter probe developed specifically for salt applications has been described by cook and Ames (1979). The device consists of a straingauged stressmeter that is designed for use in a 38-mm borehole. The device is cylindrical in shape and has a tapered inner bore fitted with a brass plug. As the gauge deforms under load, a strain-gaged, axial compression beam contained in the brass plug is compressed because of the taper of the inner bore.

Cook and Ames have compared this new gauge with probably the most popular stressmeter in the United states: the Irad vibrating wire stressmeter (VWS measurement range 0.01-15 MPA - according to Pratt (1979a)). The authors report that the gauge exhibits a measuring ange three times larger than that of the vibrating wire stressmeter. The new gauge is reported to show a linear voltage output with respect to the borehole deformations induced by stress changes, unlike the vibrating wire gauge, 
which shows a nonlinear voltage output that depends on the modulus of the rock material (Schrauf, 1980). The gauge has been temperature cycled between $21^{\circ} \mathrm{C}$ and $205^{\circ} \mathrm{C}$ without the influence of external loads; a change of $\pm 0.6-m v$ change in voltage output was detected. The gauge has also been tested in salt undergoing plastic deformations; absolute stresses have been measured with an accuracy of \pm 15\%. The reported accuracy is comparable to that of other absolute stress measurement techniques that measure borehole deformations (208 according to Pratt (1979)).

The strain-gauged stressmeter is a promising development because it reportedly increases the measuring range as compared with the vibrating wire stressmeter, and because of its linear voltage output. It should be noted, however, that conventional stressmeters such as the UsBM borehole gauge and vibrating wire stress meter have performed adequately during heater tests that caused stress changes of a magnitude similar to those expected in repositories. Consequently, it is probable that the reported larger measuring range offered by the probe described abose may not be necessary. Not enough information is yet available to assess this device on the basis of short- and long-term reliability under high, variable temperatures and under different field conditions such as the presence or absence of water in the measurement hole.

\section{Modifications to Conventional stressmeters}

Stressmeters have been commonly used in the past for mining and engineering applications. The stressmeters used for these applications have not, however, been designed to meet the high-temperature and long-term reliability requirements necessary for repository applications. As a result, extensive laboratory testing, calibration, and design modifications are being performed so that conventional stressmeters will perform adequately under high-temperature environments, i.e., during heater testing and postemplacement stress monitoring. Two types of devices have generally been studied and modified so far: USBM borehole deformation 
gauges and vibrating wire stressmeters. Dodds (1979) and pratt et al. (1979) have conducted studies on conventional USBM deformation gauges and have proposed some modifications. Dodds reports that four basic modifications were made to increase the instruments' water resistance, to provide better gauge stability, and to provide easier equipment access down the drill hole for the borehole deformation gauges. Several tests have been conducted on these instruments to study, among other things, temperature effects, long-term reliability, and sensitivity. These results are not yet available but will be published in a report for the Office of Nuclear Waste Isolation (ONWI) in the near future. The studies and modifications reported by pratt et al. (1979) were conducted on both the USBM deformation gauges and vibrating wire stressmeters. Their studies suggest that the output obtained from the UsBM gauge is affected by temperature in two ways: (a) the electronics of the instrument "see" nonexistent changes in displacement as the temperatures rise, and (b) the relationship between dis.lacement and gauge output (calibration factor) changes as temperatures change. The design modifications performed on these instruments should allow stress change measurements to be made at temperatures of up to $200^{\circ} \mathrm{C}$; these modifications are described by Board et al. (1980).

Pratt et al. (1979) point out that the relationship between deformation and output (the calibration factor) also varies with temperature for the vibrating wire stressmeter. To correct for this temperature effect, the authors have developed an empirical relationship that was found to fit the in situ heater experiment data very well. Schrauf et al. (1979) suggest that each vibrating wire stressmeter should be calibrated individually in the laboratory. Laboratory calibrations in hard rock have indicated sufficiert variability between gauges to require individual gauge calibrations.

Stress changes in a repository can be monitored with a variety of borehole devices. The International Engineering Company (1979) has listed all of the stressmeters used in the past to measure changes of stress over time. 
Recent research and development efforts in the field of stress change measurements have been briefly described in this section. Some of these new developments are designed to improve conventional stressmeters such as the USBM deformation gauge to increase their reliability under high-temperature conditions. Other research efforts described include laboratory testing to understand the effects of high temperatures and the limitaticns of some conventional stressmeters. Both calibration curves and corrections for temperature effects have been developed as a result of these efforts. $A$ new stressmeter designed for use in salt has also been described. This device reportedly can measure absolute stresses as well as changes of stress with time with accuracies comparable to those of commercially available stressmeters and offers a measurement range three times larger than the range offered by vibrating wire stressmeters and USBM borehole deformation gauges. Very limited field experience has been accumulated with this instrument, however, and hence its advantages and limitations cannot be assessed thoroughly at the present time.

A novel approach used to monitor stress changes with cross-hole acoustic surveying has also been discussed in this section. This approach has some advantages over the technique usually used wherein borehole displacements are measured and related to stress changes. The cross-hole acoustic method can be used to monitor stress changes around waste canisters or other hot spots without having to be in contact with the rock mass at a given point of interest. Hence, the instruments used will not have to be designed to withstand the high temperatures that stressmeters located near the canister may have to withstand. The method can also be used to monitor changes of elastic modulus over time and to detect the presence of inhomogeneities such as fracture zones and faults.

The success of this approach will depend strongly, however, on our understanding of the thermomechanical behavior of fractures; at present, our understanding of this behavior is limited. Because this approach has been tried only once in the field, the advantages and limitations iisted here should be considered preliminary. The use of the acoustic surveying technique to 
monitor stress changes should be considered to be in the early stages of development.

The developments discussed above are related to some of the suggestions for research and development work cited in the introduction to this section: Labcratory testing, calibrations, and design modifications of existing techniques (such as the USBM gauge and vibrating wire stressmeters) have been dicussed that will improve their durability and accuracy when exposed to high temperatures. New techniques that can be used to measure stresses in nuclear waste environments are also cited. Inclusions are not yet available that can monitor stress changes that occur parallel as well as perpendicular to the borehole. However, other instruments such as the Australian Commonwealth Scientific and Industrial Research Organization (CSIRO) gauge can be used to measure stresses parallel and perpendicular to the borehole.

Stress change measurements have been used successfully in the past for mining and engineering applications. However, available stress measurement techniques have rather limited capabilities that need to be improved. The long-term, high-temperature reliability of existing instrumentation remains largely unevaluated; further testing and, if necessary, design modifications should be made. to improve the reliability of these instruments. There are no proven geophysical tools that can be used to monitor stress changes remotely. This capability is highly desirable, because it would eliminate the need for access boreholes when measuring stress changes in remote volumes of rock. A technique that could measure stress charges remotely would most likely average stress change measurements; stress changes measured at a point are often location-sensitive and may bear little relation to the actual stress changes over a representative rock volume. The development of geophysical tools that can remotely monitor stress changes is recommended. Often there is a lack of consistency between techniques used to measure stress changes. Consequently, it is difficult to separate instrumental problems from actual local variations of stress level that may be of significance. Additional research is necessary to improve our understanding of the causes of these variations, so the changes in the state of stress in time and space can be adeguately characterized. 
The containment capabilities of a repository horizon are closely related to the stability and deformation behavior of the rock mass surrounding a repository. Displacements measured around rock structures are related to the stresses causing the displacements by a parameter called rock mass deformability. Displacement and deformability measurements can provide very important information during the different stages of repository development. These measurements will be used to adequately design a repository, to validate model predictions, and to provide data needed to understand the thermal and mechanical behavior of rock masses.

Reviews of the state of the art available to measure displacements and rock mass deformability with respect to repository needs have been published recently (Cook, 1979; Pratt, 1979; Lawrence Berkeley Laboratory, 1978; International Engineering Company, 1979). In regard to displacement measurements, Pratt (1979) suggests that improvements in conventional rod extensometers (rods and anchors) are required; he also suggests that emphasis should be placed on higher resolution devices $(0.1-1 \mu)$ at least as calibration instruments that can be compared with other techniques. The Lawrence Berkeley Laboratory (1978) points out that the resolution of the best conventional extensometers is $100 \mu$ and that present extensometers become difficult or impractical to use in high-temperature fields. For displacement measurements in salt, where the expected deformation can be on the order of tens of $\mathrm{cm}$, this level of accuracy is adequate. To ensure adequate instrument performance, it is necessary to make extensive calibrations, to pay attention to the effects of hostile subsurface environments, th evaluate these devices at elevated temperatures, and to make any necessary modifications.

The International Engineering Company (1979) and Bieniawski (1978 (a) report that there is often a poor correlation between the results obtained with the different techniques available to measure rock mass deformability. Large-scale tests need to be redesigned to reduce the time and expense of 
testing. Borehole jacking tests (i.e., small-scale tests) need improvements in data analysis to improve data correlation with large-scale tests which are affected more by rock inhomogeneities and discontinuities, and hence, are believed to provide data that are more representative of the rock má.u. Pratt (1979) suggests that the various techniques available must be compared with each other to assess accuracy and precision; he also suggests that the methods used to determine deformability anisotropy be evaluated. The International Engineering Company (1979) has listed the conventional instrumentation available for displacement and deformability measurements.

Several new instruments and results from recent research efforts are described below. Four new designs of borehole probe-type extensometers are discussed below. All of them are either under current development or are currently being evaluated under field conditions. The accuracy of probe-type extensometers is affected significantly less (when compared with the accuracy of conventional rod and wire extensometers) by borehole curvature such as occurs when creep deformations affect a bedded or domed salt repository. Probe-type extensometers are not affected by stick-slip friction and anchor slippage, which frequently affect conventional rod and wire extensometers. However, probe-type extensometers cannot monitor displacements continuously over time, and most of the designs described below have not been evaluated with respect to the effects of high rock temperatures. Also described are design modifications and results of studies intended to reduce the errors induced by high variable temperatures on borehole extensometers. Results of comparisons between different rock mass deformability measurement techniques to evaluate the reliability of these techniques are also described.

\section{Distofor Borehole Extensometer}

The "Distofor" is a recently developed borehole extensometer which, unlike existing instruments, does not require the use of several tensioned rods or wires to measure displacements at a number of points along a borehole. Thus, the instrument is less likely to be affected by the "stick slip" friction that has affected conventional extensometers in 
the past. Conventional borehole extensometers used to monitor salt displacements may be particularly susceptible to stick-slip friction because of borehole curvature induced by salt creep.

The Distofor system measurements are based on the inductance of a pair of concentric electric circuits. The inner circuit is a coil, 140 mm long, mounted on a stiff rod installed down the center line of the borehole. The rod is anchored to the rock at one end of the hole. The other circuit is a corrosion-resistant ring fixed by springs against the rock. A number of reference rings and sensors can be installed in the hole up to a maximum of one pair per linear meter. Any change in position of the outer ring relative to the inner resonant circuit changes the inductance and thereby the resonant frequency of the inner circuit (Bellier and Debreuille, 1977). Laboratory resolution is $\pm 7 \mu$, giving a practical accuracy in the field of $\pm 2 \mathrm{~mm}$ for every $100 \mathrm{~mm}$ of displacement. The total range of displacement of each sensor is $120 \mathrm{~mm}$. The Distofor is unaffected by water, up to a pressure head of $150 \mathrm{~m}$. The total range of displacement of each sensor is $120 \mathrm{~mm}$. The operating temperature range is $0^{\circ} \mathrm{C}$ to $50^{\circ} \mathrm{C}$ (Bellier and Debreuille, 1977).

Bellier and Debreuille (1977) have also reported on the development of a portable extensometer (termed Extensofor) that operates on the same principle. The sensor carries inflatable packers to hold it in position against two consecutive reference rings.

Design Studies and Design Modifications

of Conventional Borehole Extensometers

The extensomiters used to measure displacements of the rock rass surrounding a repository must operate reliably under harsh environmental conditions that affect the instruments' survivability and reliability. D. J. Dodds (1979) has summarized the design studies and design 
modifications done to date on the borehole extensometers that will be used to monitor the Near surface Test Facility at Richland, Washington.

Three basic modifications have been made to the extensometer assembly to provide better waterprocfing and a more stable head configuration. Modifications were made on the instruments selected for use: the Terrametrics' multiple-position borehoie extensometer model CSLT(R). Several tests have been conducted on these instruments to determine the effect of heat on lorg-term stability and anchor creep. Some important observations made during the course of these tests are cited below. The anchor creep test showed that the anchors tested moved when heated and crept under constant temperature. In all cases, tile movement during heat-up was greater than the creep at constant temperature. Grout within the hole did not redure creep. The maximum heat-induced anchor movement observed was $0.02 \mathrm{~mm}$. This magnitude of movement is comparable to some of the snaller displacements generally detected with borehole extensometers on hard rock masses. In the case of dome or bedded salt, the dis- placements likely to occur will be 3-5 orders of magnitude higher than those measured during these tests.

other tests have shown that the invar rod expansion (invar is a type of steel with a low coefficient of thermal expansion) is nonlinear over the temperature range expected $\left(5^{\circ}-200^{\circ} \mathrm{C}\right)$. Permanent, thermally induced strains upon thermal cycling of the rods tested were also observed. Both of these effects should be studied further to determine whether the associated errors will significantly reduce the accuracy of the displacement measurements.

\section{Extenso-Deflectometer}

One of the problems likely to affect the accuracy of borehole extensometers in bedded or dome salt is that of heat-induced borehole curvature. Measurements of displacements both parallel and perpendicular to the borehole will be needed to understand adequately the displacements that occur in the rock mass surrounding the extensometer. 
A new instrument designed by the Federal Institute of Technology in Switzerland can measure displacements both parallel and perpendicular to the borehole (Kovari et al., 1979). The instrument combines in a single probe certain features of the multiple-point borehole extensometer and deflectometer, as well as features of inclinometers. The probe measures the distance change between conespherical probe contacts used to ensure accurate and repeatable measurements. The probe also measures displacements ihat occur perpendicular to the borehole axis by means of a linear voltage differential transducer (LVDT) attached to a cantilever section. The reported laboratory precision of the instrument is remarkably high: for displacements parallel to the axis, it is $\pm 1.5 \mu \mathrm{m}$, and for perpendicular displacements, it equals $\pm 2.0 \mu \mathrm{m}$.

The device, which consists of a portable probe, enables all three conponents of the displacement vector to be determined at consecutive points along the borehole. It has been utilized in several projects and has provided valuable information for better understanding of the behavior of unāerground structures.

Probe-type extensometers such as the Extenso-deflectometer are not affected by some of the problems that affect conventional borehole extensometers. Probe-type extensometers make use ot a reusable probe. They do not require that the displacements be monitored with tensioned wire or steel rods, and thus the likelihood that anchor slippage will occur is greatly reduced. Unlike rod and wire extensometers, probe extensometers are portable and reusable. Probe-type extensometers are not plagued by the inaccuracies caused by the friction between wires or rods in conventional extensometers. However, unlike the conventional extensometers, they do not have the capability to monitor deformation continuously.

\section{Sliding Micrometer}

A simplified version of the system described above has also been designed (Kovari et al., 1979). According to the authors, this tool, which is 
referred to as the "Sliding Micrometer - ISETH," may be one of the most accurate probe-type extensometers. It measures displacements only along the axis of the borehole, by measuring the change in distance between a series of anchor points, using an LVDT. This instrument also uses conespherical probe contacts that can be disengaged from the anchor points by rotating the probe $90^{\circ}$. The instrument has been tested in the field with a reported precision of $\pm 1.5 \mu$. It has a higher field precision than the Extenso-deflectometer because it is more compact and has a simpler design. The sliding micrometer is watertight up to a pressure of 10 bars. The operating temperature range of the instrument has not been reported, but it has been designed to be self-temperature compensating.

The sliding micrometer has several advantages over conventional borehole extensometers. It exhibits better sensitivity than conventional extensometers (Kovari, 1980). It can be removed from the borehole at any time and checked for proper functioning and accuracy. A portable calibration frame constructed of invar steel serves to field check its proper functioning and long-term stability. One major disadvantage of this instrument is that it is not possible to take time-continuous readings.

System for Monitoring Displacements in Three Dimensions

Smart et al. (1978) have designed a single-probe borehole instrumentation system that, like the extenso-deflectometer discussed above, can be used to measure displacements both parallel and perpendicular to the borehole axis. The instrument measures displacements parallel to the hole axis by measuring the distance between a reference magnet and magnets positioned at regular intervals along a borehole. The distance is measured using a precision chain connected to the reference magnet and to a very sensitive revolution counter. Displacements that are not parailel to the borehole axis can be measured by two inclinometers oriented orthogonally to each other and to the axis of probe. The reference magnet and the inclino- 
meters are housed in the same probe. The probe has been tested in the laboratory using a simulated borehole. The authors report that the average errors calculated from the simulation survey were "acceptable."

Large numbers of reference points can be located in a borehole and monitored to understand the deformation process around a repository. This instrument may prove useful to monitor creep displacements associated with bedded or domed salt that induce curvature of the borehole axis. Three-dimensional deformation monitoring capabilities will be very useful in understanding rock mass behavior around a repository, particularly in the case of domed or bedded salt.

\section{Sonic Probe Extensometer}

Another portable extensometer (i.e., a removable probe is the sensor) has been recently developed (Hawkes and Kwitowski, 1979). This device uses the travel time of sonic waves to measure relative displacements between the borehole collar and reference magnets anchored along the hole. A removable magnetostrictive probe is inserted in the hole. When the probe is energized, local stress waves are created by the magnetic fields surrounding each magnetic anchor point. These local stress waves travel down the probe length; the differences in their arrival times are determined using a high-frequency oscillator. To calculate the relative displacements, the travel time of the stress wave is multiplied by the stress wave speed.

The reported resolution of the instrument is $0.025 \mathrm{~mm}$. The instrument is limited to measurements within $7 \mathrm{~m}$ of the borehole. Inaccuracies in the extensometer are a result of slight variations in the stress wave speed along the probe, variations from probe to probe, and small temperature influences. Like other probe-type extensometers, this instrument cannot measure displacements continuously over time. An assessment of the impact of temperature on stress wave speed and on the system's electronics should be made to ascertain the usefulness of this instrument for repository studies. 
Temperature effects can induce significant errors in displacement measurements obtained with conventional borehole extensometers. The errors can be significant even when materials with low coefficients of thermal expansion are used, particularly when temperatures are highly variable. pratt et al. (1979) report that the use of downhole thermocouples in conjunction with low-expansion thermal alloys has been successful in correcting for thermal effects on rod-type extensometers. The thermocouples were strategically placed on the basis of tests conducted on a borehole extensometer in a heated, simulated borehole. The overall accuracy of the extensometer system after evaluation and calibration under temperatures as high as $200^{\circ} \mathrm{C}$ is $0.02 \mathrm{~mm}$; this compares favorably with the accuracy capabilities of $0.1 \mathrm{~mm}$ proposed by Gnirk and Boskins (1979) for displacement measurements.

\section{Assessment of In Situ Tests for Rock Mass Deformability}

One problem still awaiting clarification in the rock mechanics field is the reliability and accuracy of in situ rock mass deformability tests (Bieniawski, 1978a). The parameter of rock mass deformability relates the level of stress existing in a rock mass to the deformation induced by the stress level. This parameter provides very important information needed to design underground openings. It is generally accepted that in situ tests reflect the behavior of larger and hence more representative volumes of rock in comparison with the data obtained from testing small samples in the laboratory. It is also generally accepted that there are a number of uncertainties associated with in situ tests that need to be evaluated.

Bieniawski (1978a, 1979) has compared several in situ methods for rock deformability determinations in an effort to evaluate the reliability of these techniques and to identify the type(s) of techniques that should be used to obtain a reliable measure of rock deformabllity. Eight different 
techniques for rock mass deformability were tested: plate bearing tests, large flat jacks, small flat jacks, Goodman jacks, tunnel relaxation, petite sismique, ${ }^{1}$ seismic velocities, and rock quality indexes. On the basis of more than 100 in sity tests, the author made the following observations and recommendations.

(1) Considerable scatter of the results was obtained even under fairly uniform rock conditions.

(2) To obtain reliable results, at least two different types of in situ tests should be selected: the plate bearing test and the Goodman jack are recommende. 2 .

(3) The petite sismique can be used to provide a check on the measurement techniques above and can be used to determine the continuity of rock mass conditions throughout the area of the proposed engineering project.

(4) The value of the in situ modulus of deformation obtained with a Goodman jack can vary significantly depending upon the corrections used. The Heuze-Salem correction takes into account the differing stiffnesses of the rock and jack platens; results of Goodman jack data using this correction agree quite well with the petite sismique results. The Hustrulid correction, which corrects for the contact angle between the jack loading platens and the borehole surface, gives values that are closer to the flat jack results.

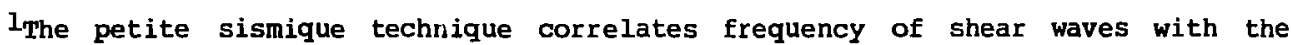
in situ static modulus of deformation. It was developed in Europe several years ago and is now beginning to be used in the United states. 
Bieniawski (1978b) has proposed the use of the Geomechanics Classification system to estimate the in situ modulus of deformation with an accuracy better than 208. The Geomechanics Classification system empirically relates rock conditions that are easily obtainable in the field with observed rock mass behavior. On the basis of South African case histories, a linear relationship was developed between the modulus of deformation $\left(E_{M}\right)$ and the rock mass rating (RMR).

$$
E_{M}=1.76 \times R M R-84.3
$$

The reported correlation coefficient of this empirical equation was found to be 0.9612 on the basis of 21 observations.

One advantage of this method is that it can provide an estimate of rock mass deformability prior to the construction of shafts and exploratory adits. However, the reliability of the method under differing geologic environments still needs to be evaluated.

Modified Dilatometer: The dilatometer is a standard borehole tool for measuring rock mass deformability. One problem associated with the use of the dilatometer has been that it is difficult to establish the relationship of the deformability measurements and the rock mass fractures affecting these measurements. Deformability measurements are very much dependent on the characteristics of the fractures present. Goodman (1980) has reported the ongoing development of a dilatometer that includes an impression packer that can be used to obtain an impression of the fractures in situ. A measure of fracture frequency, fracture aperture, and fracture orientation can be obtained from the packer; thus, a more complete measure of deformability can be obtained. 
Experts in the area of geotechnical field instrumentation have recently published a listing of suggested methods for adequately measuring the deformability of rock masses. The Commission on standardization of Laboratory and Field Tests of the International society of Rock Mechanics (1979) has proposed methods that can be used, as well as appropriate methodologies for performing the tests and reducing the data. A similar listing has been published by the Commission to provide guidelines for the selection and use of borehole extensometers (International Society of Rock Mechanics, Commission on Standardization, 1978).

There are many measurement techniques available for measuring rock mass deformability and displacements. However, most of these instruments will not meet the requirements of long-term reliability, particularly under high and variable temperature fields, that will affect the rock mass surrounding a repository.

Improvements in rock extensometer design that should increase the likelihood of long-term instrument reliability have been described. New probe-type extensometers that are not affected by borehole curvature and that can measure displacements in three dimensions have also been discussed. A new probe-type extensometer with better precision than conventional borehole extensometers has also been presented. Comparisons between different rock deformability techniques are presented that improve our knowledge and understanding of the reliability that these techniques can offer. The results of the research efforts and new instrumentation designs discussed address some of the problems and suggested instrumentation needs listed previously. None of the new instruments described were designed for repository application; therefore, their long-term reliability and their high-temperature behavior remain largely unevaluated. These promising developments need to be further developed and evaluated under field conditions so that the potentials and limitations of each with respect to repository applications can be established. 
The presence of fractures in the rock mass that will surround nuclear waste repositories will have a very important and deleterious impact on rock mass properties. Fractures characteristically control the rock mass behavior of rocks such as basalts and granites because these rocks usually have associated pervasive fracture systems. Fractures and other discontinuities tend to make the rock mass less suitable as a repository site; that is, the permeability and deformability of the rocks increase and the rock mass strength is reduced. Fractures are also largely responsible for the anisotropic nature of rock masses. The presence of fractures also causes the rock mass properties to become highly stress dependent (Lawrence Berkeley Laboratory, 1978). As the aperture of existing fractures is changed or as new fractures develop, the properties of the rock mass also change. Clearly, fracture characterization measurements provide very important information necessary for evaluating and monitoring a nuclear waste repository site.

Most of the instrumentation specialists who have assessed the instrumentation capabilities available for characterizing fractures in rock agree that these are not sufficiently developed for repository applications. Bruce (1979) proposes that high priority should be given to improving the existing capabilities of mapping fractures in rock. Deficiencies in our ability to adequately characterize fractures hamper the efforts to model fracture effects, according to the authors. The Lawrence Berkeley Laboratory (1978) recommends improvement in single- and crosshole methods used to delineate fracture characteristics. Pratt (1979) points out that the techniques used to quantitatively measure the frequency, nature, and geometry of fractures are in the very early stages of development. The available techniques lack penetration into the rock mass. Pratt also suggests that techniques that send signals between boreholes and the surface of the excavation will be required for fracture analysis. This type of surface borehole instrumentation will be useful for characterizing at depth those fractures that are mapped in the walls of the repository rooms. Pratt also suggests that a high priority 
should be given to research and development efforts relevant to the instrumentation needed to monitor changes in fracture properties with time and temperature. An understanding of the behavior of fracture aperture with changes in temperature is critical to our understanding of permeability around a repository. Yet, as the Lawrence Berkeley Laboratory (1978) indicates, there are no existing instruments for measuring and monitoring fracture aperture, even though the technology is straightforward. Gnirk and Hoskins suggest that for fracture permeability considerations, the measurement accuracy required to measure fracture aperture should be $1 \mu$.

Bruce (1979) has suggested that the feasibility of a large-scale test facility to determine the physical properties of large blocks of fractured rock at relevant temperatures and stresses should be determined. Our current understanding of fracture behavior under changing temperature and stress conditions is poor; therefore, tests on rock samples sufficiently large to adequately represent a fractured rock mass are recommended. Bruce proposes that a large sample size should be tested; the suggested capabilities for the proposed facility range up to:

- Pore and confining pressure - 1000 bars

$\begin{array}{ll}\text { - Temperature } & -300^{\circ} \mathrm{C} \\ \text { - Stress difference } & -1500 \text { bars } \\ \text { - Strain rates } & -10^{-3} \text { to } 10^{-6} / \mathrm{sec}\end{array}$

Based on the brief review of recommendations and observations presented above, it can be concluded that significant improvements need to be made in the area of fracture characterization and monitoring. A few new developments relevant to fracture characterization studies are described below. Additional fracture instrumentation developments have been listed by Mao and Ramirez (1980).

A new probe developed to detect fine fractures in lock is described below. Also discussed are new developments that can be used to measure the permeability of rock masses. Advances in the area of acoustic emission interpretation that suggest that the technique can be used to monitor and 
predict repository stability as well as fracture development are also discussed. The permeability associated with fractures will probably control seepage flow. in the vicinity of a repository. Fracture flow will be a very important factor for repositories built in rocks such as basalts and granites that have very small permeabilities when intact, but can have large permeabilities along the fractures that are characteristically associated with them. Apps et al. (1979) report on the development of a new system to characterize fracture permeability; this system has been successfully tested in the basalts found on the Hanford Reservation. It siruld be pointed out that our intent has not been to search for new developments in hydrogeological instrumentation. Consequently, only two new developments pertaining to hydrogeological instrumentation are presented.

\section{Sensitive Detector of Fine Fractures}

Fine fractures, i.e., those with very small apertures, have always been very difficult to detect on boreholes when conventional borehole logging tools are used. A new probe developed by the Swedish Geological survey is reported to be a promising detector of fine fractures (Nelson et al., 1979). The tool consists of two electrodes that function both as current and as potential electrodes. The positive electrode is separated from the negative electrode by a 12-mm thick insulator and is much shorter. The insulator is used to force the current to flow through the borehole wall and through any discontinuities present - not through the liquid filling the borehole. Because of its shorter length, the positive electrode is more sensitive to variations in the surrounding resistance because the negative electrode has less variable contact resistance.

According to the authors, the probe's sensitivity is highly dependent on probe geometry and the annulus between the insulator and the borehole wall. The ability to interpret the signal obtained in terms of fracture spacing, fracture orientation, depth, and aperture is also in need of improvement. Therefore, improvemer' $s$ in the understanding and design of the probe are necessary. 
Shallow jointing or loosening of the rock mass can be expected to occur around underground repositories as the openings are constructed. This zone of shallow jointing is of importance because of the impact it will have on the stability and permeability of the rock mass. Existing methods for assessing the degree of fracturing and depths of the fractures yield only information about a point or an exposed surface in the rock mass. Stephansson et al. (1979) have presented a theory of wave propagation that may be useful for extending knowledge of fractures intersected by the boreholes into the remaining rock mass.

The theory is based on the propagation of elastic waves around the tips of open joints. At the tip of the joint, the waves are refracted. The velocity of the rock mass is determined from the travel time curves and the intercept times on the time axis of these curves. Once the distances between the joints are obtained by any of the available methods, the depth of the joints from the surface can be calculated.

The theory has been tested using artifically jointed concrete blocks, on rockwalls in open pits and in tunnel walls. Close agreement was found between the calculated depth of jointing and the experimental values obtained from the concrete blocks tested. However, the calculated depth of joints was less than the depth of natural joints in the walls of the open pit test site. The authors suggest that the discrepancy can be explained by the presence of high horizontal stresses, which close the fractures and allow acoustic coupling across the fracture. Consequently, a shorter wave path results in erroneous predictions. A much closer agreement was obtained in the tunnels of an iron ore mine where high horizontal stresses are not likely to exist. The results obtained using this new theory suggest that additional field experiments are warranted to increase our understanding of the effects of differing geologic conditions on the accuracy of the predicted fracture depths. 
Acoustic emission is associated with the release of stored strain energy resulting from small-scale displacements such as occur during the formation of cracks in a rock mass. The interpretation of acoustic emission data associated with underground openings has been predominantly qualitative in nature during the last few years. The usefulness of such measurements in monitoring underground structures has thus been limited. Recent developments, however, may eventually make acoustic emission a useful tool for remotely monitoring the stability of underground repositories.

Recent theoretical, experimental, and field investigations conducted by the U.S. Bureau of Mines suggest that sudden, catastrophic deformations, such as rock failures that endarger underground openings, may be predicted using the acoustic emission method.

Brady (1978) states that theoretical studies that were later corroborated by laboratory and field investigations predict that a seismic anomaly precedes rock bursts or roof falls in mines. The seismic anomaly consists of an increase in the number of seismic events occurring in the immediate vicinity where the failure will be nucleated. This increase is then followed by a dramatic decrease of seismicity in a broad region that surrounds the location of impending failure. The dimensions of this region allow a preliminary estimate of the time to failure (measured from the time seismicity began), as well as an estimate of the energy that will be relased at the instant of failure. Recent data also suggest that the time interval during which the seismicity anomalies appear increases in relation to the magnitude of the impending failure. 
A new system that reportedly reduces the length of time required to conduct permeability tests has been described by Apps et al. (1979). The system consists of a packer-mounted probe containing pressure and temperature sensors. A typical test consists of lowering the system to the test zone and inflating the packers. A pressure pulse is generated by the inflation of the packers. The shut-in pressure is then monitored until it reaches a stable value. Permeability can be calculated from the magnitude of the pressure pulse generated by the inflation of the packers, because this is a function of the permeability. Using this probe, the length of time required for the test is significantly reduced. According to the authors, pressure equilibration is more rapid than in test systems that rely on measurements of water level in a standpipe, because pressure equilibration depends only on flow into or out of the rock caused by the compressibility of the water.

As was pointed out previously, Pratt (1979) and the Lawrence Berkeley Laboratory (1978) suggest that significant improvements are needed to obtain the instrumentation required to characterize fractures. A few new fracture characterization techniques have been listed in the preceding paragraphs and by Mao and Ramirez (1980). These new developments address some of the recommendations and observations made by Pratt and the Lawrence Berkeley Laboratory. However, a comparison of the new instrumentation developments listed with the research and development recommendations made by these authors may suggest that many of these recommendations remain largely unfulfilled. The existing techniques that can be used to characterize fractures only provide information along a line defined by the borehole axis or only provide qualitative information about those fracture segments not intersected by the repository walls or exploratory boreholes. Laboratory facilities that can handle large samples (approximately $1 \mathrm{~m}$ in size) and determine their physical properties at relevant pressures, temperatures, and stresses have not been developed. However, increasingly larger samples are being tested in a few laboratory facilities. Additional research and development efforts will be needed to enhance the capabilities of the existing fracture characterization technology to the level required for repository applications. 
Canisters emplaced in nuclear waste repositories generate heat for long periods of time. As a result, both rock temperatures and some rock mass properties change over time. Repository sites in bedded or domed salt undergo enhanced creep rates. Repositories in basalt or other polymineralic rock types may be subjected to thermally induced spalling or intragranular fractures. Thermal expansion and subsequent contraction can affect some of the properties of fractured or jointed rock masses, such as fracture permeability, because the aperture of fractures or joints can change. Because rock mass behavior and repository performance are dependent on thermomechanical behavior, both accurate temperature measurements and representative measurements or estimates of several thermal parameters are necessary to ensure adequate repository performance.

The Lawrence Berkeley Laboratory (1978) and Gnirk and Hoskins (1979) propose that temperatures should be measured to an accuracy of $0.1^{\circ} \mathrm{C}$. Pratt (1979) and the Lawrence Berkeley Laboratory agree that this level of accuracy can be achieved with good thermocouples, but they indicate that long-term instrument drift may be a problem. The International Engineering Company (1979) indicates that there are no in situ techniques designed for underground use to measure emissivity, thermal heat transfer coefficient, and thermochemical properties. The measurement of all these parameters requires tine development of new techniques.

A few new techniques and modifications to existing instruments are described below. Other recent developments have been listed by Mao and Ramirez (1980).

Methodology for Determining In Situ Thermal Conductivity and Diffusivity

In situ measurements of thermal conductivity can be made by borehole probes; no in situ methods exist for measuring the thermal diffusivity of 
rocks. Accurate measurements of thermal conductivity and diffussivity can be obtained in the laboratory (International Engineering Company, 1979). Jeffry et al. (1979) have proposed and tested a different method for determining the in situ thermal properties of a rock mass. Their method consists of a least-squares approximation of data calculated on the basis of a finite line source model. The least-squares scheme analyzes the temperature data from in situ heater tests and calculates the values that give the best fit between the temperature measurements and the calculations based on assumed values of thermal conductivity and diffusivity. Using this methodology, thermal conductivity and diffusivity values have been obtained that are only slightly higher than the corresponding laboratory values.

The method described above has some advantages over existing methods used to obtain thermal conductivity and diffussivity. The probe used to measure thermal conductivity obtains values at one point, which may or may not be representative of the rock mass; on the other hand, the method presented above makes use of temperature profiles within the rock mass that are likely to be more representative of the rock mass as a whole. Thermal diffussivity values have generally been measured in the laboratory or calculated from thermal conductivity data; the methodology presented above offers the capability of inferring in situ diffussivity values on the basis of temperature measurements.

Modifications to Conventional Thermocouples

Design studies have been performed on conventional thermocouples to determine what modifications would be required for the instruments to perform adequately under the enviromental conditions expected during testing at the Near Surface Test Facility at Richland, Washington. The parameters that have to be met by these thermocouples are: temperature $5^{\circ}-200^{\circ} \mathrm{C}$ and possible dripping water. Two basic modifications to the thermocouple assembly have been incorporated. These modifications allow easier installation, better sensor-to-rock coupling, waterproofing, 
complete access to instruments for repairs or replacements, and the ability to produce temperature profiles of the entire rock. These modifications include installing the thermocouples in individual Teflon tubes and filling the borehole with grout.

Very few new developments in the area of thermal measurements have been listed in this section or by Mao and Ramirez (1980). A comparison of these lists of new developments with the proposed research and development goals listed at the beginning of this section suggests that several important goals have not been met. No techniques designed for underground use have been developed to measure in situ thermal heat transfer coefficients, thermoelastic constants, or thermochenical properties. However, laboratory measurements of these three parameters can be made. More research is necessary to indicate the relative importance of these parameters, the accuracy with which they ought to be measured, and, if appropriate, develop in sitú measurement techniques. Emphasis should be placed on evaluating the effects of rock mass discontinuities on the accuracy of laboratory measurements. Improvements in the capabilities of laboratory facilities to handle representative rock samples under relevant temperatures and stress conditions are also needed. Research work pertaining to the long-term stability of thermocouples is also lacking. On the positive side, a new methodology for obtaining representative in situ values of thermal diffusivity and conductivity has been described, along with some improvements in existing thermocouple assemblies. 
Several instrumentation research and development projects are currently in process or have recently been terminated. Consequently, no published reports are available that contain information pertaining to these projects. Nevertheless, a list of these ongoing projects is presented below to apprise the reader of these efforts. Many of these projects are designed to reduce or eliminate deficiencies associated with the use of existing techniques for repository applications. Most of the projects in the list were obtained from the report, Earth Science Technical Plan for Disposal of Radioactive Waste in a Mined Respository, Appendix D, by the Office of Nuclear Waste Management and the U.S. Geological Survey, DOE/TIC-11033 (draft), April 1980.

\section{Commercially Available Monitoring Techniques}

Waite (1980) reports that an overall assessment of conventional "off the shelf" instrumentation that can be used to monitor the repository has been conducted recently. The report discusses the existing instruments that can be used to monitor the repository during nuclear waste emplacement and afterwards.

\section{- Telemetry System for Borehole Instrumentation}

Borehole-emplaced instruments may be required to monitor the repository after closure. Conventional borehole instruments use cables that may seriously affect the sealing effectiveness of borehole plugs by creating leakage paths along which water and radionuclides may migrate. Henderson (1980) reports that Develco, Inc., has conducted studies to develop a wireless telemetry system for borehole instruments that does not use cables. The system has been developed and field tested. 
The U.S. Geological Survey is developing new geophysical techniques and modifying conventional instruments that can be used for identifying small-scale inhomogeneities and structures in rock masses. A magnetic susceptibility probe has been developed to detect moisture variations in hard rock such as salt or granite. A neutron activation probe that has the potential of measuring moisture content with a high degree of precision is being tested. Surface seismic and geoelectrical methods are being modified so that the special problems of repository exploration can be addressed.

Assessment and Development of High-Frequency

Electromagnetic Borehole Techniques*

The U.S. Geological Survey is involved in a project designed to assess the capabilities and limitations of high-frequency electromagnetic borehole techniques for exploration of evaporites and crystalline rocks. Borehole equipment for radar and point-to-point transmission measurements will also be developed and tested.

Development of a Radar Borehole Probe*

The Lawrence Livermore National Laboratory is developing a borehole antenna that can be used to achieve a directive bean of radiation. This capability is needed to locate anomalies in the vicinity of one borehole (size, distance, and location). Existing borehole antennas do not provide an adequate directional capability.

*Obtained from Appendix D of Earth Science Technical Plan for Disposal of Radioactive Waste in a Mined Repository. 
The U.S. Geological Survey is conducting a project designed to evaluate, test, and develop borehole instruments that can be used to measure stress, deformation, and strength. The purpose of the project is to develop and refine rock mechanics techniques that can be used to characterize repository sites.

Assessment of Existing Geophysical Technigues That Can Be Used To Characterize Fractures*

The Lawrence Berkeley Laboratory will assess the usefulness of different surface, subsurface, and borehole geophysical techniques that can be used to delineate and characterize fracture systens. High-frequency electromagnetic studies of the fracture system using closely spaced boreholes will be conducted in the stripa mine.

\section{Comparison of Hydraulic Eracturing and Overcoring Stress Measurement*}

The Iawrence Berkeley Laboratory will use the hydraulic fracturing technique and the overcoring technique to measure absolute stresses at Stripa and to riotermine how well the results of these different methods agree.

\section{Instrumentation Development for In Situ Testing*}

The Sandia Laboratories are involved in a project designed to develop transducer systems for in situ stress, borehole closure, and extensometers. A thermal probe for the determination of in situ thermal properties is also under development.

Hobtained from Appendix D of Earth Science Technical Plan for Disposal of Radioactive Waste in a Mined Repository. 
Ohio State University will determine the instrumentation requirements for in situ testing and will define any developmental needs that may exist. An assessment of "off the shelf" instrumientation available to fulfill in situ testing needs will be provided. Recommendations pertaining to the development or modification of techniques necessary to provide reliable instrumentation will also be provided.

State-of-the-Art Review of Rock Mechanics Measurement Techniques*

Terra Tek has conducted a state-of-the-art review of techniques for the short- and long-term measurement and monitoring of stress, strain, and displacements at elevated room temperatures. Limitations of commercially available instruments will be identified. Techniques currently under development will also be identified and discussed.

\section{Repository Instrumentation Development*}

The Office of Nuclear Waste Isolation will sponsor research and development efforts aimed at fulfilling the research and development needs identified by the Ohio state University study, previously listed. These developments will predominantly address problems of reliability, stability, and functional/hostile environment compatibility.

\section{Applicability of Acoustic Methods To Monitor Fractures*}

The Iawrence Berkeley Laboratory will determine whether acoustic methods can be used in the near field to monitor fracture development or fracture slip as a rock mass is heated. This experiment is being conducted at the Spent Fuel Test Facility in Climax granite.

*Obtained from Appendix D of Earth Science Technical Plan for Disposal of Radioactive Waste in a Mined Repository. 
Apps, J., Doe, R., Doty, B., Galbraith, R., Kearns, A., Kohrt, B., Long, J., Monroe, A., Narasimhan, T. N., Nelson, P., Wilson, C. R., and P. A. Witherspoon. Geohydrological Studies for Nuclear Waste Isolation at the Hanford Reservation. Berkeley, Calif.: Lawrence Berkeley Laboratory, LBL-8764, 1979.

Bellier, J., and P. Debreuille. "Three New Instruments for Measurements in Tunnels," Proceedings of the International Symposium on Field Measurements in Rock Mechanics. Zurich: April 4-6, 1977.

Bieniawski, z. T. "A Critical Assessment of Selected In Situ Tests for Rock Mass Deformability and stress Measurements." Proceedings of the 19th Symposium on Rock Mechanics. Reno, Nev.: University of Nevada, 1978a.

Bieniawski, z. T. "Determining Rock Mass Deformability : Experience from Case Histories." Int. J. Rock Mech. Min. Sci., Vol. 15, pp. 237-247, 1978b.

Bieniawski, Z. T. "A Comparison of Rock Deformability Measurements by Petite Sismique, the Goodman Jack and Flat Jacks." Proceedings of the Rapid Excavation and Tunneling Conference. Atlanta, Ga.: 1979.

Blackwood, R. L. "An Instrument To Measure the Complete Stress Field in Salt Rock or Coal in a single Operation." Proceedings of the International Symposium of Field Measurements in Rock Mechanics, pp. 137-150, 1977. Zurich: April 4-6, 1977.

Blackwood, R. L. "Diagnostic Stress-Relief Curves in stress Measurement by Overcoring." Int. J. Rock Nech. Min. Sci., Vol. 15, pp. 205-209, 1978. 
Board, M., Nelson, P., Schrauf, T., Dubois, A., Lingle, R., and H. Pratt. "Hodification and Thermal Corrections for stress and Displacement Instrumentation - Stripa, Sweden." American Society of Civil Engineers Spring Convention, Portland, Ore. Preprint 80-167, 1980.

Brady, B. T. Prediction of Failures in Mines - An Overview. Washington, D. C.: U.S. Bureau of Mines, RI-8285, 1978.

Bruce, W. Laboratory Measurements Workshop. Proceedings of a Workshop on Thermomechanical Modeling for a Hardrock Waste Repository. F. Holzer and L. Ramspott (eds.). Livermore, Calif.: Lawrence Livermore Laboratory, UCAR-10043, 1979.

Buckner, G. O. Method and Apparatus for Acoustic Well Logging of Earth Boreholes. United states Patent 4,140,994, 1979.

Cook, C. W., and E. S. Ames. "Borehole Inclusion Stressmeter Measurements in Bedded Salt." Austin, Texas: 20th U.S. Symposiun on Rock Mechanics, 1979.

Cook, N. G. W. "Field Measurements Techniques: Status and Needs." Proceedings of a horkshop on Thermomechanical Modeling for a Hardrock Waste Repository. F. Holzer and L. Ramspott (eds.). Livermore, Calif.: Lawrence Livermore Laboratory, UCAR-10043, 1979.

Daniels, J. J., Scott, J. H., and R. J. Hite. "Analysis of Borehole Geophysical Data in an Evaporite Sequence at Salt Valley, Utah." SPWLA Twentieth Annual Logging Symposium. Tulsa, Okla.: 1979. Transaction $\mathbf{M}$.

D'Appolonia, E., and D. E. Shaw. "Melding Geophysics into Underground Construction." Proceedings of a Conference on site Exploration in Rock for Underground Design and Construction. Washington, D. C.: U.S. Department of Transportation, FBwA-TS-79-221, pp. 4-12, 1979. 
Dines, K. A., and R. J. Lytle. "Computerized Geophysical Tomography." Proceedings of the IEEE, Vol. 67, No. 7, 1979.

Dodds, D. J. "Design and Fabrication of Rock Instrumentation for the Near-Surface Test Facility." Basalt Haste Isolation Project Annual Report - 1979. Hanford, Wash.: Rockwell Hanford Operations, 1979.

Duvall, H. I., and J. R. Aggson. Least Square Calcuiation of Horizontal Stresses from More Than Three Diametral Deformations in Vertical Boreholes. Washington, D. C.: U.S Bureau of Mines, RI 8414, 1980.

Enever, J. R., Mckavanagh, B., and G. Carson. "Some Applications of Instrumentation in the Australian Mining Industry." Proceedings of the International Symposium on Field. Measurements in Rock Mechanics. Zurich: April 4-6, 1977.

Farr, J. B. "High-Resolution Geophysics as an Aid to the Engineer." Proceedings of a Conference on Site Exploration in Rock for Underground Design and Construction. Washington, D. C.: U.S. Department of Transportation, FHWA-TS-79-221, pp. 13-40, 1979.

Fowler, J. C., and L. A. Rubin. Mine Roof Stratigraphy Using

Electromagnetic Radar- Washington, D. C.: Department of Energy, FE-9142-1, 51 pages, 1978.

Gnirk, P., and E. Hoskins. "In Situ Test and Model Validation." Proceedings of a Workshop on Thermomechanical Modeling for a Hardrock Waste Repository. F. Holzer and I. Ramspoti (eds.). Livermore, Calif.: Lawrence Livermore Laboratory, JCAR-10043, 1979. 
Goodman, R. E. "Summary of State-of-the-Art Paper on Measurement of Rock Properties by In-Situ Probes." Proceedings of a Conference on Site Exploration in Rock Underground Design and Construction. Washington, D. C.: U.S. Department of Transportation, FHWA-TS-79-221, pp. 51-55, 1979.

Goodman, R. "Personal Communication." Berkeley, Calif.: University of California, 1980.

Hawkes, I., and A. J. Kwitowski. "Mine Roof Borehole Extensometers." Austin, Texas: 20th U.S. Symposium on Rock Mechanics, 1979.

Henderson, N. "Personal Conmunication." Columbus, Ohio: Battelle Memorial Institute, Office of Nuclear Waste Isolation, 1980.

Hirashima, K., and A. Koga. "Determination cf Stresses in Anisotropic Elastic Medium Unaffected by Boreholes from Measured strains or Deformation." Proceedings of the International Symposium on Field Measurements in Rock Hechanics. Zurich: April 4-6, pp. 173-182, 1977.

Hustrulid, พ. Instrumentation/Measurement Techniques and Philosophies for Nuclear Waste Repositories. Berkeley, Calif.: Lawrence Berkeley Laboratory, Publ. 246, 1978.

International Engineering Company. Review of Geotechnical Measurenent Techniques for a Nuclear Waste Repository in Bedded Salt. Report prepared for the Lawrence Livermore Laboratory, Livermore, Calif., UCRL-15141, 1979.

International Society of Rock Mechanics Comnission on Standardization of Laboratory and Field Tests. "Suggested Methods for Determining In Situ Deformability of Rock." Int. J. Rock Mech. Min. Sci., Vol. 16, pp. 195-214, 1979. 
International Society of Rock Mechanics Commission on Standardization of Laboratory and Field Tests. "Suggested Methods for Monitoring Rock Movements Using Borehole Extensometers." Int. J. Pock Mech. Min. Sci., Vol. 15, pp. 305-317, 1978.

Jaeger, J. C., and N. G. W. Cook. Fundamentals of Rock Mechanics. Iondon: Chapman Hall, Ltd., 1976.

Ranagawa, T., Hayasi, M., and H. Nakasa. "Estimation of Spatial Geostress Components in Rock Samples Using the Raiser Effect of Acoustic Emission." Proceedings of the Third Acoustic Emission Symposium, Tokyo: 1976.

Rehrman, R. F. Development of a Shallow-Penetration Acoustic Reflection Technique for Mining Geology. Boulder, Colo.: Westinghouse Electric Corporation. Contract $\mathrm{HO} 262002$ for the U.S. Bureau of Mines, 1977.

Reller, G, V. "Review of Radio Wave Methods for Probing Earth." Proceedings of a Conference on Site Exploration in Rock for Underground Design and Construction. Washington, D. C.: U.S. Department of Transportation, FHWA-TS-79-221, Pp. 56-64, 1979.

Keys, w. s. "Borehole Geophysics in Igneous and Metamorphic Rocks." Proceedings of the SPWLA Twenthieth Annual Logging Symposium, Tulsa, Okla. Transaction 00 , June 1979.

K. Rovari. "Personal Communication." Zurich: Federal Institute of Technology, 1980 .

Kovari, K., Amstad, C., and J. Koppel. "New Developments in the Instrumentation of Underground Openings." Proceedings of the Rapid Excavation and Tunneling Conference. Atlanta, Ga.: 1979. 
Lawrence Berkeley Laboratory. "Geotechnical Assessment and

Instrumentation Needs for Nuclear Waste Isolation in Crystalline and Argillaceous Rocks." Sympösium Proceedings. Berkeley, Calif.: LBL-7096, July 16-20, 1978 .

Leckenby, R. L. "Personal Communication." Denver, Colo.: U.S. Bureau of Mines, Denver Mining Research Center, March 27, 1980.

Lytle, R. J. "Personal Communication." Livermore, Calif.: Lawrence Livermore Laboratory, 1980.

Lytle, R. J., Dines, K. A., Laine, E. F., and D. L. Lager. Electromagnetic Cross-Borehole Survey of a Site Proposed for an Urban Transit Station. Livermore, Calif.: Lawrence Livermore Laboratory, DCRL-52484, 1978.

Mao, N., and A. Ramirez. "New Developments in Measurement Technology Relevant to the Studies of Nuclear Waste Repositories in Bedded Salt." Livermore, Calif.: Lawrence Livermore National Laboratory, UCID (in preparation), 1980.

Nelson, P., Paulson, B., Rachiele, R., Anderson, L., Schrauf, T., and w. Hustrulid. "Preliminary Report on Geophysical and Mechanical Borehole Measurements at Stripa." Berkeley, Calif.: Lawrence Berkeley Laboratory, Technical Information Report No. 16, LBL-8280, 1979.

Nolting, R. N., and R. E. Goodman. "In Situ Stress Measurements by Overcoring Cast-In Place Epoxy Inclusions." Proceedings of the Fourth Int. Soc. Rock Mechanics. Montreux, Switzerland: 1979.

office of Nuclear Waste Management and United States Geological Survey. Earth Science Technical Plan for Disposal of Radioactive Haste in a Mined Repository. Washington, D. C.: Department of Energy, IrIC-11033 (Draft), Appendix D, April 1980. 
Paulsson, B. N. R., and M. S. King. "Between-Hole Acoustic Surveying and Monitoring of a Granitic Rock Mass." Accepted for forthcoming publication by the International Journal of Rock Mechanics and Mining Sciences, Vol. 17, 1980 .

Pratt, H, Field Measurements Workshop. Proceedings of a Workshop on Thermomechanical Modeling for a Hardrock Waste Repository. F. Holzer and L. Ramspott (Eds.). Livermore, Calif.: Lawrence Livermore Laboratory, UCAR-10043, 1979.

Pratt, H., Schrauf, T., Hustrulid, W., and E. Simonson. "A Large-Scale In Situ Study To Determine Temperature, Deformation and Stress Fields Associated with Heater Experiments in Crystalline Rock." Proc. of the Fourth Int. Soc. Rock Mechanics. Montreux, Switzerland: September 1979.

Repsher, R. C., and D. J. Black "Long-Term Rock Noise Plotting Techniques." Washington, D. C.: U.S. Bureau of Mines, RI-8399, 1979.

Ribacchi, R. "Rock Stress Measurements in Anisotropic Rock Masses." Proc. of the International Symposium on Field Measurements in Rock Mechanics. Zurich: April 4-6, 1977.

Romig, P. R., and J. K. Applegate. "Geophysics Applied to Nuclear Waste Disposal Site Characterization." Paper presented at the 1980 Soring Conference of the Am. Soc. Civil Engineers. Portland: 1980 .

Rubin, L. A., Fowler, J. C., and G. G. Marino. Multiple Borehole Radar Subsurface site Investigation by Radar, Phase_2. Springfield: Ensco, Inc., PB-288073, 1978.

Schrauf, T. W. "Personal Communication." Salt Lake City, Utah: Terra Tek, University Research Park, 1980. 
Schrauf, T. W., Pratt, H. R., Hustrulid, W. A., Simonson, E. R., Nelson, P., Dubois, A., Binnall, E., and R. Haught. Instrumentation Evaluation, Calibration and Installation for the Heater Experiment at Stripa. Berkeley, Calif.: Lawrence Berkeley Laboratory, LBL-8313, 1979.

Sjogren, B, Ofsthus, A., and J. Sandberg. "Seismic Classification of Rock Mass Qualities." Geophysical Prospecting, 27, pp. 409-442, 1979.

Smart, B. G. D., Singh, R. N., and A. R. Issac. "A Borehole Instrumentation System for Monitoring Strata Displacement in Three Dimensions." Int. J. Rock Mech. Min. Sci., Vol. 15, pp. 77-85, 1978.

Stephansson, O., Lande, G., and A. Bodare. "A Seismic Study of Shallow Joi nted Rocks." Int. J. Rock Mech. Sci. and Geomech. Abstr., 16, pp. 319-321, 1979.

Unterberger, R. R. "Locating Discontinuities in Geologic Environments by Radar and Sonar Probing Techniques." Proceedings of the Rapid Excavation and Tunneling Conference, Vol. 2, pp. 1071-1088, 1979.

Waite, D. "Personal Communication." Office of Nuclear Waste Isolation, Columbus, Ohio: Batelle Memorial Institute, 1980.

Witherspoon, P. A., Nelson, P., Doe, T., Thorpe, R., and B. Paulson. Rock Mass Characterization of Nuclear Waste in Granite. Berkeley, Calif.: Lawrence Berkeley Laboratory, LBL-8570, 1979. 